\title{
The distribution of phi-features in pronouns
}

\author{
Marjo van Koppen
}

Received: 15 August 2008 / Accepted: 13 September 2010 / Published online: 2 December 2011

(C) The Author(s) 2011. This article is published with open access at Springerlink.com

\begin{abstract}
This paper focuses on the question which phi-features are associated with pronouns and how these features are distributed over their internal structure. I argue that pronouns contain Participant and Individuation features (Harley and Ritter 2002). The Participant features and the Individuation features are merged as discrete sets of features which can be targeted for syntactic operations like Agree independently from the other phi-features associated with pronouns. These feature sets are merged and end up on the maximal projection of the pronoun as one feature bundle.

The core data of this paper are constituted by Complementizer Agreement (CA) in Dutch dialects (cf. Haegeman 1992; Zwart 1993). In (the mostly West-Germanic) dialects with CA, the subject of an embedded clause agrees with both the finite verb, and with the complementizer introducing the embedded clause. I show that there are two types of CA dialects. In the first type, the complementizer and the finite verb have the same ending. In the second type, the so-called Double Agreement (DA) dialects, however, the complementizer and the finite verb do not have the same affix. What has gone unnoticed in the literature until now is that these two types of CA dialects can be distinguished on the basis of two more properties: CA in the DA dialects is sensitive to (i) extraction of the embedded subject pronoun to a higher clause and (ii) modification of the subject pronoun by a focus particle. I argue that the differences between these two types of CA can be explained if $\mathrm{C}$ does not target the same Goal in these dialects. In the DA dialects CA is the result of a Probe agreeing with the Participant features inside the pronominal structure, whereas CA in the other dialects reflects agreement with the top node of this pronominal structure.
\end{abstract}

Keywords Agree and Agreement · Internal structure of pronouns · C-agreement . Microvariation

M. van Koppen $(\bowtie)$

Utrecht Institute of Linguistics-OTS, Utrecht University, Trans 10, 3512 JK Utrecht, The Netherlands e-mail: J.M.vanKoppen@uu.nl 


\section{Introduction}

In the past few decades a fair amount of attention has been devoted to the syntax of pronouns (cf. among others, Postal 1966; Cardinaletti and Starke 1999; Roehrs 2005). Several issues have been addressed: the question of whether pronouns are phrasal or not (Abney 1987; Cardinaletti and Starke 1999; Cardinaletti 1998; Corver and Delfitto 1999; Roehrs 2005; Postal 1966), the question of what the exact internal structure of pronouns is if they are indeed assumed to be phrasal (cf. especially Déchaine and Wiltschko 2002; Cardinaletti and Starke 1999; Roehrs 2005), and the question of which features are associated with pronouns (cf. among many others, Harley and Ritter 2002; Cardinaletti and Starke 1999). I will follow the vast amount of literature which takes pronouns to be phrasal. Although the conclusions I draw in this paper can presumably be accommodated in other analyses of the internal structure of pronouns, I build on the proposal by Déchaine and Wiltschko (2002).

This paper focuses on the question which phi-features are associated with pronouns and how these features are distributed over their internal structure. I argue, following Harley and Ritter (2002), that pronouns contain Participant features and Individuation features. I show that the Participant features and the Individuation features are merged as discrete sets of features which can be targeted for syntactic operations like Agree independently from the other phi-features associated with pronouns. These discrete feature sets are merged in the course of the derivation and end up on the maximal projection of the pronoun as one feature bundle.

The core data of this paper are constituted by so-called Complementizer Agreement (CA) in Dutch dialects. CA has been extensively discussed in the literature (cf. among many others, Haegeman 1992; Zwart 1993; Carstens 2002; Hoekstra and Smits 1997). In (the mostly West-Germanic) dialects with CA, the subject of an embedded clause agrees with both the finite verb of that embedded clause, and with the complementizer introducing the embedded clause. An example is provided in (1).

$$
\begin{aligned}
& \text {... datt-e me toffe jongens benn-e } \\
& \text { that-PL we cool guys are-PL } \\
& \text { '... that we are cool guys' }
\end{aligned}
$$

South Holland Dutch

There are two types of CA dialects. In the first type, the regular CA dialects, the complementizer and the finite verb have the same ending, an $e$-affix in the case of the example in (1). ${ }^{1}$ In the second type, usually referred to as the Double Agreement (DA) dialects, however, the complementizer and the finite verb do not necessarily have the same affix. What has gone unnoticed in the literature until now, is that these two types of CA dialects can be distinguished on the basis of two more properties: CA in the DA dialects is sensitive to (i) extraction of the embedded subject pronoun to a higher clause and (ii) modification of the subject pronoun by a focus particle.

\footnotetext{
${ }^{1}$ The $e$-ending in the examples actually represents a schwa. I will use the terms ' $e$-affix' or 'schwa-affix' to refer to this ending.
} 
This paper is organized as follows. Section 2 provides the core data of this paper: Agreement between the complementizer and the subject pronoun in the regular CA dialect of Tegelen on the one hand and in the DA dialect of Hellendoorn on the other. Tegelen Dutch will be used as an example of a regular dialect and Hellendoorn Dutch as a representative example of a DA dialect. Section 3 introduces the main theoretical assumptions: (i) Déchaine and Wiltschko's (2002) analysis of the internal structure of pronouns, and (ii) Harley and Ritter's (2002) proposal concerning the feature makeup of pronouns. Section 4 provides the theoretical core of this paper. I show that the complementizer in Tegelen Dutch and the one in Hellendoorn Dutch do not agree with the same set of features. This accounts for the diverging patterns of CA in these dialects. Section 5 gives two arguments in favor of this analysis. First of all, the analysis accounts for the differences concerning extraction and modification of the subject between regular and DA dialects. Secondly, I discuss CA with coordinated subjects. I show that there is a striking similarity between DA patterns and CA with the first conjunct of a coordinated subject. This parallel behavior provides additional support for the core proposal of how phi-features are distributed over pronouns. Finally, Section 6 discusses some alternative analyses of the phenomena discussed in this paper as well as the problems of these analyses. Section 7 concludes.

\section{Core data: Agreement with pronouns}

\subsection{Two types of complementizer agreement}

Complementizers in several West-Germanic dialects agree with the subject of the embedded clause, displaying CA (cf. among others, Zwart 1993; Carstens 2002). In most dialects, the agreement morpheme appearing on the complementizer is the same as the one appearing on the finite verb. Consider for instance the examples from Tegelen Dutch in (2). ${ }^{2}$

$$
\begin{aligned}
& \text { a. ... de-s/ } * \text { det doow morge kum-s } \\
& \text { that-2P.SG } / \text { that you } 2 \mathrm{P} . \mathrm{SG} \text { tomorrow come-2P.SG } \\
& \text { '... that you will come tomorrow' } \\
& \text { b. ... de-s } / * \text { ? det auch doow merge kum-s } \\
& \text { that-2p.sg } / \text { that also you }{ }_{\mathrm{SG}} \text { tomorrow come-2P.SG } \\
& \text { '... that you too will come tomorrow' }
\end{aligned}
$$

c. DOOW denk ik de-s/ *det de wedstrijd winnen zal-s.

you $_{\mathrm{SG}}$ think I that-2P.SG/ that the game win will-2P.SG

'YOU, I think will win the game.'

These data show that an $s$-affix appears on both the complementizer and the finite verb to express agreement with a second person singular subject. Furthermore, as

\footnotetext{
${ }^{2}$ Note that Dutch does not have a that-trace effect.
} 
the examples in $(2 b-c)$ show, respectively, neither modification nor extraction of the subject has an influence on this agreement morphology.

I mainly focus on a subtly different set of CA dialects, namely those dialects that display DA. Recall that DA refers to the situation in which the agreement affix is sensitive to the structural position of the finite verb/complementizer relative to the subject. This pattern is exemplified in (3)-(5).

a. Wiej bin-t den besten!

Hellendoorn Dutch

we are-agr the best

'We are the best!'

b. * Wiej binn-e den besten! we are- ${ }_{\text {AGR }}$ the best

a. * Bin-t wiej den besten? are-AGR we the best

b. Binn-e wiej den besten? are- ${ }_{A G R}$ we the best

'Are we the best?'

... darr-e / *dat wiej den besten bint/ * binn-e!

that- ${ }_{\mathrm{AGR}} /$ that we the best are- ${ }_{\mathrm{AGR}} /$ are- ${ }_{\mathrm{AGR}}$

'... that we are the best!'

The agreement on the finite verb in the DA dialects is dependent on whether the subject precedes it, in which case it inflects with a $t$-affix, or follows it, in which case it carries an $e$-affix. The agreement on the complementizer is similar to the agreement on the finite verb in the verb-subject order. CA in DA dialects like Hellendoorn Dutch also differs in two other crucial respects from CA in the regular CA dialects. Recall that CA in Tegelen Dutch is not affected by movement of the subject or modification of the subject by a focus particle, see $(4 b-c)$ above. CA in Hellendoorn, however, is sensitive to movement and modification of the subject, as is illustrated in the examples in (6) and (7) below.

a. ... dat zölfs wiej de wedstrijd wint that even we the game win

'... that we even win the game'

b. ...* *darr-e zölfs wiej de wedstrijd wint that-1P.sG even we the game win

(7) WIEJ denkt Jan dat/ * darr-e die pries ewönnen hebt, nie ZIEJ. we think Jan that/ that-1P.sg that prize won have not they

'WE John thinks won that prize, not THEM.'

These examples show that modification by a focus particle and extraction of the subject result in an obligatory absence of the agreement morphology on the complementizer.

To summarize, we can distinguish between two types of CA: Type $1 \mathrm{CA}$, found in regular agreement dialects like Tegelen Dutch. The agreement affix on the complementizer is similar to the affix found on the finite verb. Furthermore, this type of CA is 
not sensitive to movement of the subject or modification of the subject. Secondly we have Type $2 \mathrm{CA}$, which is found in DA dialects like Hellendoorn Dutch. In these dialects, the agreement morphology on the complementizer equals the agreement morphology on the verb in VS contexts. This type of CA is sensitive to extraction and modification of the subject in the sense that it disappears under these conditions.

\subsection{The phi-feature specification of the affixes in Hellendoorn Dutch}

The examples in (2)-(4), repeated here as (8)-(10), show that there are two agreement affixes associated with first person plural subjects; namely $-e$ and $-t$. The $e$-ending can only appear on the complementizer and on the finite verb preceding the subject. The $t$-ending is restricted to contexts in which the finite verb follows the subject, i.e. in SVO and CSOV word orders. ${ }^{3}$

a. Wiej bin-t den besten!

we are- ${ }_{A G R}$ the best

'We are the best!'

b. *Wiej binn-e den besten!

we are-agr the best

(9) a. *Bin-t wiej den besten? are- $_{\text {AGR }}$ we the best

b. Binn-e wiej den besten?

are-AGR we the best

'Are we the best?'

... darr-e/ $*$ dat wiej den besten bint $/ *$ binn-e!

that- ${ }_{\mathrm{AGR}} /$ that we the best are- ${ }_{\mathrm{AGR}} /$ are- ${ }_{\mathrm{AGR}}$

'... that we are the best!'

A straightforward assumption on the basis of these data is that there are two distinct affixes associated with the first person plural in Hellendoorn Dutch: a $t$-affix which appears in SVO and CSOV word orders, and an $e$-affix which appears on the complementizer and the verb in VSO orders (cf. among others Zwart 1993, 1997; van Craenenbroeck and van Koppen 2002). I will show that this assumption makes the wrong predictions and that the feature specification of the $e$-affix is different from that of the $t$-affix. In particular, I argue that the $e$-affix in this dialect has the feature specification [1P.SG], whereas the $t$-affix is the elsewhere affix. First consider the agreement paradigm in Hellendoorn Dutch represented in table (11). ${ }^{4}$

\footnotetext{
${ }^{3}$ Embedding without a complementizer is not possible in (these varieties of) Dutch.

${ }^{4}$ The alternation between the zero and the $t$-affix in the second person singular in the verbal paradigm is a general property of Dutch and several of its dialects, like Hellendoorn Dutch. However, it is not related to CA or DA as found in the East Netherlandic dialects; see van Craenenbroeck and van Koppen (2003) for additional argumentation. There is a set of East Netherlandic dialects, like the dialect of Winterswijk, which make this clear. Winterswijk Dutch has the exact same DA pattern as in Hellendoorn Dutch; see (i) (from Deunk 1977).
} 
(11)

\begin{tabular}{|c|c|c|c|}
\hline Subject Features & Complementizer & Verb VSO order & $\begin{array}{l}\text { Verb SVO/ } \\
\text { CSOV order }\end{array}$ \\
\hline 1P.SG & $\varnothing$ & $\varnothing$ & $-e$ \\
\hline 2P.SG & $\varnothing$ & $\varnothing$ & $-t$ \\
\hline 3P.SG & $\varnothing$ & $-t$ & $-t$ \\
\hline 1P.PL & $-e$ & $-e$ & $-t$ \\
\hline 2P.PL & $\varnothing$ & $-t$ & $-t$ \\
\hline 3P.PL & $\varnothing$ & $-t$ & $-t$ \\
\hline
\end{tabular}

This table represents three agreement paradigms in Hellendoorn Dutch. The first one, in the second column of this table, provides the paradigm of CA. This paradigm has only one overt affix, namely the $e$-ending in the first person plural. The third column shows the agreement paradigm of finite present tense verbs in the VSO word order. In the fourth column the agreement paradigm of finite verbs in the present tense in the SVO and CSOV order is provided. Hoekstra and Smits (1997) argue that $\mathrm{CA}$ appears iff the agreement affix for a certain person/number combination is not a portmanteau affix for agreement and tense. ${ }^{5}$ This also holds for Hellendoorn Dutch. Consider the paradigm in (12) of the finite verb gaan 'to go' in the present and past tense in inversion contexts in this dialect. ${ }^{6}$

\begin{tabular}{|l|l|l|l|}
\hline & CA & present tense & past tense \\
\hline $1 \mathrm{p} . \mathrm{sg}$ & dat & goa & gong \\
\hline 2p.sg & $d a t$ & goa & gong \\
\hline 3p.sg & $d a t$ & gie- $t$ & gong \\
\hline $1 \mathrm{p} . \mathrm{pl}$ & darr-e & goar-e & gong-e \\
\hline 2p.pl & dat & goa-t & gong-en \\
\hline 3p.pl & dat & goa-t & gong-en \\
\hline
\end{tabular}

The agreement paradigm of Hellendoorn Dutch has (at least) three agreement affixes: an $e$-affix, a $t$-affix, and an $e n$-affix. The $e$-affix occurs just with first person (singular and plural) subjects. This means that there are three logical feature specifications for this affix: first person, first person plural, or first person singular. Van Craenenbroeck and Van Koppen (2002) argue that the feature specification of this affix is first person since the $e$-affix appears both in the first person singular and the first person plural. However, there is a problem with this assumption. Consider the examples in (13).

(i) a. Wij wil-t nò̀ hoes hen gòòn.

Winterswijk Dutch we want-AGR1 to home to go

'We want to go home.'

b. Will-e wij nòò hoes hen gòòn?

want-AGR2 we to home to go

'Do we want to go home?'

However, this dialect does not show the second person alternation that Hellendoorn Dutch does. The second person singular inflection on the finite verb is always -ste in Winterswijk Dutch independent of word order (cf. Deunk 1977).

${ }^{5}$ An anonymous reviewer notes that this affix is a portmanteau affix for person and number. This is indeed the case, but this does not affect the option to have CA. The affix still expresses 'pure' phi-features.

${ }^{6}$ Note that the final / $\mathrm{t}$ / of the complementizer dat cannot be considered an agreement affix comparable to the $t$-affix on the finite verb. It is simply the final consonant of the complementizer itself as is evidenced by the fact that it does not appear with other complementizers like $o f$ 'if/whether'. 

a. ... darr-e wiej en Marie oonszelf in de spiegel ziet that- $_{\text {AGR }}[\text { we and Marie }]_{1 P . P L}$ ourselves in the mirror see
'... that we and Marie see ourselves in the mirror'
b. ...* darr-e/ dat Marie en wiej oonszelf in de spiegel ziet that- ${ }_{\mathrm{AGR}} /$ that $[\text { Marie and we }]_{1 \mathrm{P} . \mathrm{PL}}$ ourselves in the mirror see
'... that we and Marie see ourselves in the mirror'

The first person plural pronoun in this example is coordinated with a third person singular proper name. In the (a) example, the first person plural pronoun constitutes the first conjunct of the subject, whereas in the (b) example it is the second conjunct of the coordinated subject. The feature specification of the coordinated subject is first person plural in both cases, as is shown by the first person plural reflexive in both (13a) and (13b) (cf. also among others, Corbett 2006; van Koppen and Rooryck 2008). If the feature specification of the $e$-affix is first person, it is expected to occur in both the (a) and the (b) example, as the feature specification of the subject is the same in both cases, i.e. first person plural. We have to conclude from the fact that the $e$-affix can occur in the (a) example but not in the (b) example that the feature specification of this affix is not simply first person. The same reasoning holds if we assume that the feature specification of the $e$-affix is first person plural. Again, for the configuration in both (13a) and (13b), it holds that the feature specification of the subject is first person plural in both cases. Hence we would expect the affix to appear in both sentences. So, also the hypothesis that the feature specification of this affix is first person plural is refuted by the data in (13).

At this point, we are left with just one other logically possible feature specification for the $e$-affix, namely first person singular. This seems to be an even more problematic assumption since in neither of the sentences in (13) is the feature specification of the subject first person singular. However, I show that this assumption accounts for the full range of data from Hellendoorn Dutch. I argue that the $e$-affix in (13a) reflects the agreement relation between $\mathrm{C}^{\circ}$ and the first person singular features associated with the role of speaker of the first person plural pronoun. Put differently, I will show that in example (13a) the complementizer agrees with the discrete set of features associated with the participant role of speaker. As I discuss in Sect. 5, the $e$-affix cannot occur on the complementizer in example (13b), as in this case the first person plural pronoun is not in the first conjunct of the coordinated subject and, as I will show, the relevant features are not close enough to the complementizer to trigger $\mathrm{CA}$.

A question that remains to be answered at this point is why the $e$-affix, given this assumption, does not appear with first person singular subjects in the VS order. Presumably this is due to the fact that the $e$-affix has a zero-allomorph that is used when the first person singular subject follows the complementizer or the finite verb. The idea that the $e$-affix, which is actually a schwa-affix, has a zero-allomorph is quite plausible given the fact that it is followed by the first person singular pronoun $i k$ which begins with a vowel. The process in which a schwa is reduced to zero under the influence of a vowel is frequently attested (cf. van Oostendorp 1998, and references cited there). Furthermore, there are dialects with a paradigm similar to Hellendoorn 
Dutch, like for instance Winterswijk Dutch, in which the schwa-affix is present in the first person singular in all possible word orders. So, for instance the following forms are found for the verb to live: lev-e ik literally, 'live- $e$ I' and $i k$ leve literally, 'I live- $e$ ', both meaning 'I live'.

To summarize, in Hellendoorn Dutch the $t$-affix acts as an elsewhere affix. The $e$-affix (together with its zero-alternate) reflects the phi-feature specification of first person singular. These rules for affix insertion are provided in (14).

$$
\begin{aligned}
& {[1 \mathrm{p} . \mathrm{sg}] \quad \rightarrow-e /-0} \\
& {[\mathrm{pl}, \text { past tense] }} \\
& {[\text { elsewhere }]-e n} \\
& \rightarrow-t
\end{aligned}
$$

\section{The internal make-up of pronouns}

This section makes explicit my assumptions concerning the internal structure of pronouns. There are various proposals in the literature arguing that pronouns (or at least plural pronouns) are internally complex (cf. Cardinaletti and Starke 1999; den Dikken et al. 2001; Rooryck 2006; Déchaine and Wiltschko 2002; Harley and Ritter 2002; Vassilieva and Larson 2005). This paper adopts Déchaine and Wiltschko's (2002) proposal, in which pronouns maximally consist of three layers: DP, PhiP, and NP. However, there are also pronouns that are PhiPs or even NPs. I argue that the Dutch pronouns are PhiPs. Furthermore, I discuss which phi-features are associated with pronouns. Basically following the proposal by Harley and Ritter (2002), I claim that pronouns contain Participant and Individuation features. The Participant features reflect the Speaker or Addressee role, the Individuation features define whether a pronoun is plural or not. Finally, I combine those two proposals arguing that the Participant features are base-generated as a discrete set of features in the left periphery of the pronominal projection, i.e. in Spec,PhiP, whereas the individuation features are merged lower in the structure.

3.1 The internal structure of pronouns: Déchaine and Wiltschko (2002)

Déchaine and Wiltschko (2002) (henceforth D\&W) propose that there are three types of pronouns: pro-DPs, pro-PhiPs and pro-NPs, see (15)-(17) respectively (cf. D\&W: 410).

pro-DPs

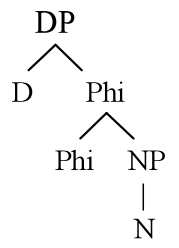




$$
\text { pro-PhiPs }
$$

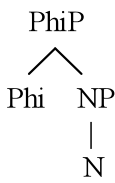

(17) pro-NPs

$$
\text { NP }
$$

These three types of pronouns each have different characteristics. Pro-DPs differ from pro-PhiPs and pro-NPs in that they have D-syntax. They cannot be used in predicate positions and they behave like R-expressions. Pro-NPs on the other hand, have an unambiguous N-syntax. They can only be used as predicates. The behavior of proPhiPs can be positioned somewhere in between that of pro-DPs and pro-NPs and comes closest to what we normally associate with pronouns: they are variables for binding theory.

I argue that pronouns in Dutch are pro-PhiPs. The most important characteristic of pro-PhiPs is that they can be used as bound variables. This is illustrated in (18) for all personal subject pronouns in Dutch. ${ }^{7}$

a. Ik voelde dat de vijand mij zag en jij ook.

I felt that the enemy me saw and you too

'I felt that the enemy saw me and you did too.'

b. Wij voelden dat de vijand ons zag en zij ook. we felt that the enemy us saw and they too

'We felt that the enemy saw us and they did too.'

c. Jullie voelden dat de vijand jullie zag en wij ook. you $_{\mathrm{PL}}$ felt that the enemy you $\mathrm{PL}_{\mathrm{L}}$ saw and we too

'You felt that the enemy saw you and we did too.'

d. Jij voelde dat de vijand je zag en ik ook. you $_{\mathrm{SG}}$ felt that the enemy you $\mathrm{SG}$ saw and I too

'You felt that the enemy saw you and I did too.'

e. Hij voelde dat de vijand hem zag en ik ook. he felt that the enemy him saw and I too

'He felt that the enemy saw him and I did too.'

f. Zij voelden dat de vijand hun zag en wij ook. they felt that the enemy them saw and we too

'They felt that the enemy saw them and we did too.'

\footnotetext{
${ }^{7}$ Rullmann (2004) notes that these examples are not equally grammatical with a bound variable interpretation for all speakers of English. D\&W note the same for French speakers. This also seems to be true for Dutch speakers.
} 
All these examples can have both a strict and a sloppy reading. Rullmann (2004) provides several other cases in which pronouns act as bound variables. I will provide one of his examples and show that the same examples can be construed for Dutch. First, consider the example in (19).

(19) We all think we are smart.

This example can have two meanings, represented in (20).

a. $\forall \mathrm{x}[\mathrm{x} \in W E \rightarrow \mathrm{x}$ thinks that WE are smart $]$

b. $\forall \mathrm{x}[\mathrm{x} \in W E \rightarrow \mathrm{x}$ thinks that $\mathrm{x}$ is smart $]$

The embedded pronoun has a non-variable reading, which is provided in (20a). The second interpretation of the example in (19) forces a variable reading of the embedded pronoun. In other words, under the second interpretation, the embedded pronoun is a bound variable. Rullmann (2004) provides a way to force the bound variable reading of the embedded pronoun. Consider the examples in (21) (from Rullmann 2004: 161).
a. We all think we're the smartest person in the world.
b. ${ }^{\#}$ We are the smartest person in the world.
c. $\mathrm{Al}$ and I both believed we were going to be elected president.
d. ${ }^{\#} \mathrm{Al}$ and I were going to be elected president.

In the (a) and the (c) example, the embedded pronoun necessarily has a bound variable reading. It cannot have a non-variable reading, as the example with the deictic, non-variable reading of the pronoun leads to an infelicitous sentence, as can be seen in the examples (21b) and (21d). These examples are infelicitous because the pronoun is plural and the predicate needs a singular subject. These examples can also be used in Dutch, showing that Dutch plural pronouns can also be used as bound variables. Consider the examples in (22).

a. We denken allemaal dat we het slimste jongetje van de klas zijn. we think all that we the smartest boy of the class are

'We all think we are the smartest kid of the class.'

b. ${ }^{\#}$ Wij zijn het slimste jongetje van de klas. we are the smartest boy of the class

'We are the smartest kid of the class.'

c. Jullie denken allemaal dat jullie het slimste jongetje van de klas zijn. you $_{\mathrm{PL}}$ think all that $\mathrm{you}_{\mathrm{PL}}$ the smartest boy of the class are

'You think you are the smartest kid of the class.'

d. \#Jullie zijn het slimste jongetje van de klas. $\mathrm{you}_{\mathrm{PL}}$ are the smartest boy of the class

'You are the smartest kid of the class.'

e. Zij denken allemaal dat zij het slimste jongetje van de klas zijn. they think all that they the smartest boy of the class are 'They think they are the smartest kid of the class.' 
f. \#Zij zijn het slimste jongetje van de klas. they are the smartest boy of the class

'They are the smartest kid of the class.'

To sum up, personal pronouns in Dutch are pro-PhiPs according to the classification of D\&W (2002). ${ }^{8}$ I adopt the structure D\&W (2002) propose for pro-PhiPs in the remainder of this paper, cf. (16) above. The following sections show which features are present at which part of the pro-PhiP structure.

3.2 The phi-feature sets present in the pronominal projection:

Harley and Ritter (2002)

Harley and Ritter (2002) (henceforth H\&R) suggest that the phi-features present in pronouns are not unorganized groups of features. Rather, they argue that these features are ordered in a feature geometry. The geometry groups together natural classes of morphological features and defines the hierarchies amongst these classes. This enables them to analyze the pronominal systems of a large sample of (unrelated) languages and to capture several universals concerning pronouns. The geometry also accounts for the data concerning first language acquisition of personal pronouns. I will not recapitulate their argumentation here; I refer the reader to the original paper.

A second important ingredient of H\&R's analysis is that they propose to assume the conceptual categories 'Participant', 'Individuation' and 'Class' as the basic features, rather than the more standard categories of 'person', 'number', and 'gender'. The notion of Participant diverges slightly from the notion of person. Participant reflects the features of the role of speech participant, which arguably always includes the value for person, but, also in some cases a value for number. H\&R assume that there is no dependency between the Participant features and the Individuation features. The feature geometry proposed by H\&R is provided in (23) below.

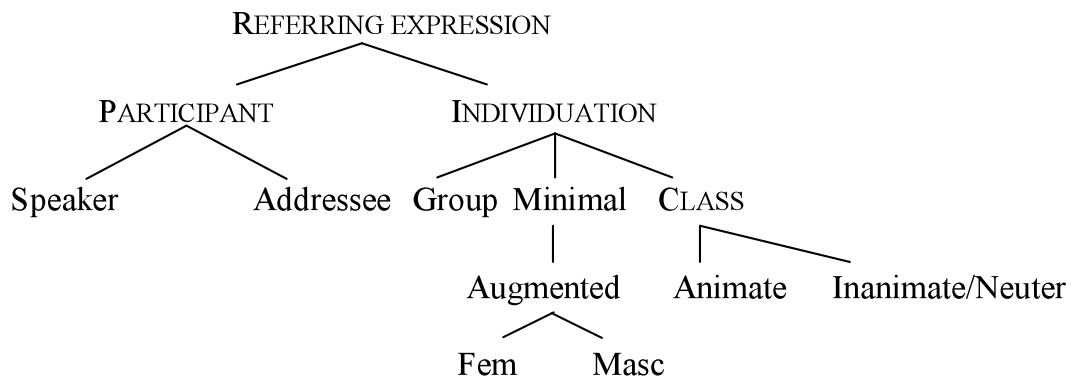

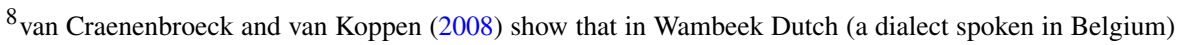
strong pronouns are pro-DPs rather than pro-PhiPs. This difference is not surprising given the fact that the pronominal system in Wambeek Dutch differs significantly from the pronominal system of standard Dutch in other respects as well. Wambeek Dutch allows for clitic doubling of strong subject pronouns, which is impossible in standard Dutch. Furthermore, Wambeek Dutch, in contrast to standard Dutch, has clitic pronouns besides strong and weak pronouns. Standard Dutch only has weak and strong pronouns.
} 
Although the proposal of H\&R does not explicitly state at which level of representation the morphological feature geometry is present, it is interesting to note that according to this view, the phi-features associated with pronouns are not simply unordered bundles of features. It is, however, not entirely clear if, and if so, how the geometry is part of the pronominal projection. The remainder of this paper addresses this question and argues that the Participant features and the Individuation features initially do not constitute one (ordered or unordered) bundle of features. I argue that these two sets of features start out in discrete positions and merge later in the derivation. My main focus will be on the Participant features. More specifically, I propose that the Participant features occupy Spec,PhiP (see Sect. 3.1 above). The Individuation features I assume to be situated in a hierarchically lower position. Although the precise location of these features is beyond the scope of to this paper, several hypotheses arise: the features can be positioned in the NP, or one could assume that PhiP is actually a cover term for two projections, the highest being ParticipantP and the lower one IndividuationP.

The question arises which feature values the Participant features and the Individuation features can have. According to Harley and Ritter (2002), the category Participant has the dependents 'speaker' or 'addressee'. The Individuation category has the dependents 'group' and 'minimal'. The final category for class features has the dependents 'animate' and 'inanimate'. As the final category does not play a role in this paper, I will leave it out of the discussion. I assume that when the Participant role of the pronoun is that of the speaker, the value of the Participant features is first person singular. ${ }^{9} 10$ This means that both the plural and the singular first person pronoun contain a singular part: the Participant features are always singular. This is in accordance with the meaning of first person plural pronouns. A first person plural pronoun does not constitute a plurality of first person singulars (cf. also den Besten 1996; Iljic 1994; Lyons 1968). Rather, the meaning of a first person plural pronoun is that there is a group which minimally contains the speaker. When the Participant role of the pronoun is that of addressee, I take the value of the participant features to be second

\footnotetext{
${ }^{9}$ Although the speaker is usually singular, there appears to be one exception. Cysouw (2001), quoting Mühlhäusler and Harré (1990), shows that there is one usage in which the speaker appears to be plural, namely in so-called mass speaking. An example of this is a crowd chanting we are the champions. The question arises if the speaker is indeed plural in this case or whether each person chanting we are the champions uses we referring to himself as the singular speaker in a set with all the others that are chanting with him.

${ }^{10}$ Note that I take the value singular to be part of the feature inventory, rather than assuming that singular arises as the default value for number, as is usually the case. Note, however, that the data presented in example (13) in Sect. 2.2 show that singular should indeed be a discrete feature value in order to account for the data. Furthermore, in the literature it has been argued that singular is not simply anti-plurality or vice versa, that plurality is anti-singularity, which is expected when singular is the unmarked value for number and plural the marked value. Sauerland, Anderssen, and Yatsushiro (2004), for instance, argue that semantically speaking, plural is not the same as anti-singular. They show that the meaning of the plural includes the singular. Sauerland (2004) and Cysouw (2001) also argue that the feature singular is marked, as it singles out an atom, whereas plural is not constrained by the inherent presupposition that it refers to an atom. Plurals can refer to both atoms and non-atoms. When this argumentation is on the right track, and singular and plural are not mutually exclusive, both concepts are necessary as (semantic) primitives of the grammar. When both concepts are needed in the semantic part of the grammar, then arguably both concepts are also present in the morphological/syntactic part of the grammar.
} 
person. The addressee features are not specified for number, as the addressee role, in contrast to the speaker role, is not necessarily singular or plural (cf. also Cysouw 2001: 70-71).

The Individuation head specifies whether the pronoun refers to a minimal group or to a larger group. When the pronoun is referring to a minimal group, I assume that the value of the Individuation features is singular; when on the other hand it is referring to a larger group, it is specified for plural.

\subsection{Combining Déchaine and Wiltschko (2002) with Harley and Ritter (2002)}

The next question is how the features identified by $H \& R$ are distributed over the pronominal projection put forward by D\&W. I will argue in Sects. 4 and 5 below that the Participant features are merged as a discrete bundle of features in the left periphery of the pronominal projection, more specifically in Spec,PhiP. Another question that remains to be answered is whether the Participant features should occupy a head position in the left periphery of the pronominal projection or a specifier position. There is a theory-internal reason to think that these features occupy a specifier position. As we will see in the structures in (24)-(27) below, the Participant features do not necessarily determine the feature specification of the entire phrase. From this we have to conclude that it is unlikely that these features appear on a head position (which presumably has the same feature specification as the maximal projection). ${ }^{11}$

The idea that phi-features are not merged as one unordered feature bundle is not without its precedents. Pollock (1989), Shlonsky (1989), Platzack (2004), Poletto (2000), among many others argue on the basis of various sets of data, like the behavior of subject clitics in Northern Italian dialects and complementizer agreement in West Flemish, that person and number features, or in current terms Participant and Individuation features, should be merged in separate syntactic positions. Furthermore, within the framework of Distributed Morphology (Halle and Marantz 1993), which I follow in this paper, it is assumed that evidence in favor of the presence of certain discrete syntactic positions can be obtained from the fact that these positions get phonologically realized by a discrete morpheme in certain languages. For the structure of pronouns this means that we expect the Participant features and the Individuation features to be expressed by different morphemes. This is indeed what Halle and Marantz (1994) show for Spanish pronouns: they consist of a morpheme expressing person features and a morpheme expressing number features mediated by a theme vowel. So, for instance Spanish los 'them' is argued to consist of an $l$-morpheme providing third person information and the $s$-morpheme which provides the number information (cf. Harris 1991; Bernstein 1993 for similar analyses; and cf. also Rooryck 2001, who provides similar argumentation for demonstrative pronouns and articles in Dutch). ${ }^{12}$

\footnotetext{
${ }^{11}$ I would like to thank an anonymous $N L L T$ reviewer for this suggestion.

${ }^{12}$ I would like to thank an anonymous $N L L T$ reviewer for pointing this out to me.
} 
Furthermore, let us consider the assumption that Participant features are basegenerated in the left periphery of the pronominal projection. The fact that Participant features are deictic, in the sense that their reference shifts when the speaker of a conversation shifts, makes this assumption feasible, since this means that the Participant features have to be available to the discourse. This in turn is usually taken to imply that they are situated in the left periphery (see amongst others, Bianchi 2006 and references cited there for analyses in which Person is linked to the left periphery of the clause).

In order to make the assumptions concerning the internal structure of pronouns and the distribution of phi-features over this structure explicit, I have provided the schemata in (24)-(27). As third person pronouns do not play a role in the remainder of this paper, I will leave them out of the discussion. The crucial case for the paper at hand is the structure in (25), in which there is a discrepancy between the feature specification of the Participant features and those of the complete pronoun. In this case the Participant features base-generated in the specifier position of PhiP are (first person) singular, whereas the accumulation of features in this projection is (first person) plural. This structure captures the meaning of first person plural pronouns: there is a singular speaker embedded in a group.

(24) First person singular

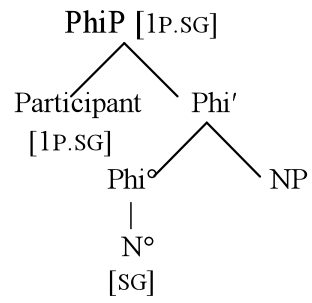

(25) First person plural

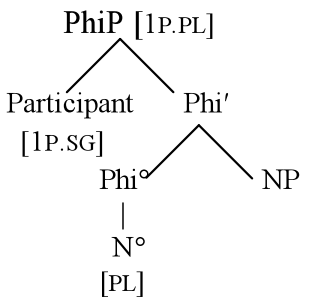

(26) Second person singular

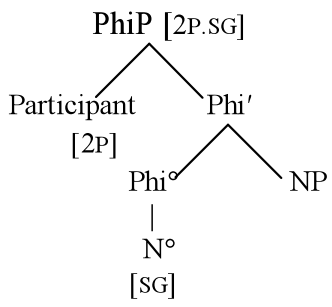




\section{Second person plural}

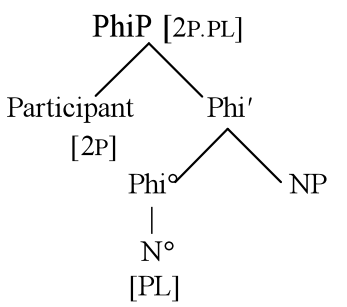

The final point I would like to address in this section is how the feature specification of the pronoun as a whole is computed. I will assume that the Participant and Individuation features merge into one bundle during the derivation and as a result percolate to the highest node in the pronominal projection. I basically follow Dalrymple and Kaplan's (1997) proposal for coordinated DPs. They argue that in coordinated structures the feature bundles and hence the feature specifications of the DP conjuncts undergo union. Translated in current syntactic terminology one could say that when a node is merged with another node the feature values of these two nodes get merged (and hence unified) as well (see also van Koppen and Rooryck 2008 for a more elaborate discussion of this proposal). ${ }^{13}$ Consider the example in (28).

(28) John and me love ourselves.

The reflexive pronoun ourselves in (28) carries first person plural features. The subject, however, consists of a third person singular part, John, and a first person singular part, $I$. The question hence arises with what entity the reflexive pronoun agrees, since neither part of the subject has first person plural features. Dalrymple and Kaplan (1997) argue that the reflexive pronoun agrees with the unified set of features of the two components of the subject, which constitutes a first person plural set: namely a set consisting of more than one entity including the speaker. Translated into minimalist terminology, one could say that within a coordination phrase the features of the conjuncts are unified by the operation merge: when the features of John are merged with the features of me, a set of features best represented as a first person plural comes into existence. I would like to suggest that the same mechanism is active in pronominal structures: the features in the pronominal projection, i.e. the Participant and the Individuation features, are unified upon merger and hence end up as one set of features on the top node of the pronominal projection, i.e. PhiP. ${ }^{14}$

The main motivation for this view on the phi-feature distribution in pronouns comes from the analysis of the CA patterns in Hellendoorn Dutch and Tegelen Dutch

\footnotetext{
${ }^{13}$ Presumably this process of percolation has to be stopped at some point in the derivation, i.e. features should not percolate infinitely.

${ }^{14}$ Note that the calculation of features in this case is not simply union of the feature specifications of the individual heads. The difference between these pronominal structures and coordination structures is that in the former case the speech participant is part of the group expressed by the individuation features and hence that union of the individuation feature does not take place. This means that a singular value for the individuation features and a singular feature on the participant feature gives a singular value on PhiP (as in (24)).
} 
which will be discussed in Sects. 4 and 5 below. In Sect. 4 I show that the assumptions discussed above elegantly account for the complex agreement data in DA dialects like Hellendoorn Dutch. Section 5 provides an argument for this point based on comparison between agreement with pronouns in Hellendoorn Dutch and agreement with the first conjunct in several other Dutch dialects. I will show that the patterns found with CA with the first conjunct, which is usually assumed to occupy the specifier position of CoP, display the same patterns as agreement with pronouns in Hellendoorn Dutch. This I take as an argument in favor of the idea that the features of the first conjunct in coordinated structures and the Participant features in the pronominal projection occupy a similar structural position, i.e. the highest specifier position in the left periphery.

\section{Double agreement: Targeting the internal structure of pronouns}

This section provides the main argument for the idea that the Participant features and the Individuation features are merged in discrete syntactic positions and that the Participant features, being merged in the left periphery, can partake in Agree relations independently of the other features in the pronominal projection. Consider again the data in (3) and (5), repeated here as (29) and (30) respectively.

a. Wiej bin-t den besten!

Hellendoorn Dutch

we are-elsew the best

'We are the best!'

b. *Wiej binn-e den besten!

we are-1P.sG the best

(30) Ik dèènke darr-e wiej den besten bin-t!

I think that-1P.sg we the best are-ELSEw

'I think that we are the best!'

Both in example (29) and in example (30), the finite verb is inflected with the $t$-affix. This affix is the elsewhere morpheme which is inserted if there is no more specific affix available. The complementizer in example (30) carries a schwa-affix. As shown in Sect. 2.2, this affix reflects first person singular features, i.e. the features belonging to the participant role of speaker. Recall, that I have argued that the-perhaps more straightforward-assumption that the feature specification of this affix is first person or first person plural leads to the wrong predictions concerning the distribution of this affix, see the discussion of and around example (13). Note, however, that the current state of affairs, i.e. where the affix expresses first person singular features, also leads to a rather unexpected situation: the complementizer agrees with a first person plural subject, while the inflection on the complementizer reflects first person singular features. In order to solve this problem, I first have to make a small detour and provide a general analysis of CA. Section 4.2 shows how an affix with first person singular features ends up on a complementizer that agrees with a first person plural subject. Thirdly and finally, I explain why this affix can only appear on the verb in the VS order, but not in the SV order. 
4.1 Complementizer agreement in Hellendoorn Dutch: Prerequisite for the analysis

Consider again the example in (30), repeated here as (31).

(31) Ik dèènke darr-e wiej den besten bin-t!

I think that-1P.sg we the best are-elsew

'I think that we are the best!'

I assume, following Carstens (2002), van Craenenbroeck and van Koppen (2002), and van Koppen (2005), that CA is a reflection of uninterpretable phi-features on $\mathrm{C}^{\circ} .^{15}$ Furthermore, I assume that features are checked via the mechanism Agree (cf. Chomsky 2000). Now let us consider the relevant part of the derivation of the example in (31), provided in (32). ${ }^{16}$

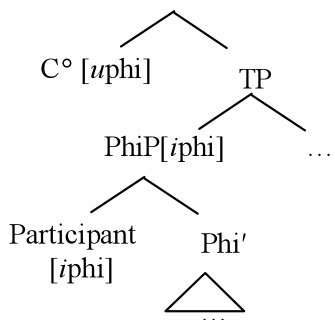

This structure represents the derivation at the point where $\mathrm{C}^{\circ}$ is merged with TP. The subject, a first person plural pronoun, occupies the specifier position of TP. The pronoun is internally complex, as I have argued in Sect. 3 above. By assumption, the specifier of PhiP contains the feature specification associated with the Speech Participant role of speaker, namely first person singular. The unified feature set of Participant features and Individuation features is present on PhiP (see Sect. 3 above). When Probe $\mathrm{C}^{\circ}$ searches its c-command domain, it encounters (at least) two Goals for phi-agreement: PhiP and Participant. If a Probe encounters more than one Goal during an application of Agree, it agrees with the most local one (Chomsky 2000). The

\footnotetext{
${ }^{15}$ A different analysis of CA, provided by, among others, Zwart $(1993,1997)$, is that the agreement affix on the complementizer spells out features that have been moved from $\mathrm{T}^{\circ}$ to $\mathrm{C}^{\circ}$. I discuss this analysis of CA in Sect. 6, but cf. also Haegeman and van Koppen (2011).

${ }^{16}$ An anonymous $N L L T$ reviewer wonders whether the phi-feature set present on C should also consist of discrete feature bundles for Participant and Individuation. Although I do not think this does makes a difference for the analysis in the main text, I would like to suggest three ways to deal with this question. The exact answer I will leave open for further research. First of all, one could think that there are several phifeature projections in the left periphery of the clause. Actually, this is what Shlonsky (1989) suggests in his analysis of West Flemish CA. Another option would be to say that there is only one functional projection associated with phi-features in the left periphery, but one could say that the phi-features on the functional head position are ordered nonetheless. This would imply that heads can have complex structures. Finally, the anonymous $N L L T$ reviewer who raised the question in the first place also provides a very interesting suggestion. S/he suggests that there might be a principled split between interpretable and uninterpretable features such that the latter ones form one unordered bundle on heads, while the former ones are merged as discrete entities in distinct syntactic locations. This would mean that the head hosting the complementizer can also host the complete set of (uninterpretable) phi-features, whereas these features have to be merged as distinct feature bundles in pronouns.
} 
question arises if we can establish whether Participant in Spec,PhiP or the features on PhiP in (32) are more local to $\mathrm{C}^{\circ}$. I argue below that these two Goals are equally local with respect to $\mathrm{C}^{\circ}$ (cf. Pesetsky and Torrego 2001; Bošković 2008 for a similar intuition that maximal projection and specifier are equally local with respect to a ccommanding Probe). I make my definition of locality specific and define locality in terms of c-command. The definitions of respectively 'equally local' and 'more local' are provided in (33) and (34).

\section{Equally local}

$\mathrm{Y}$ and $\mathrm{Z}$ are equally local to $\mathrm{X}$ iff,

(i) X c-commands both $\mathrm{Y}$ and $\mathrm{Z}$

(ii) the set of nodes that c-command $\mathrm{Y}$ is equal to the set of nodes that c-command Z

\section{(34) More local}

$\mathrm{Y}$ is more local to $\mathrm{X}$ than $\mathrm{Z}$ iff,

(i) X c-commands both $\mathrm{Y}$ and $\mathrm{Z}$

(ii) the set of nodes that c-command $\mathrm{Y}$ is a proper subset of the set of nodes that c-command $\mathrm{Z}$

The definition of c-command is given in (35).

\section{C-command}

X c-commands $\mathrm{Y}$, iff

(i) $\mathrm{X}$ excludes $\mathrm{Y}^{17}$

(ii) the first node that dominates $\mathrm{X}$, also dominates $\mathrm{Y}^{18}$

For the configuration in (32) this means that there is no locality difference between PhiP and Participant with respect to $\mathrm{C}^{\circ}$. These two Goals are equally local to $\mathrm{C}^{\circ}$ as both are only c-commanded by $\mathrm{C}^{\circ}$.

At this point the question arises of what happens when a Probe has two equally local Goals in its c-command domain. I propose that although the configuration in which there are two Goals available for one Probe arises during the syntactic derivation, it is determined at the level of morphology which one of these two Goals defines the affix spelled out on the Probe. ${ }^{19}$ Put differently, the syntactic component provides the configuration in which two Goals are available, morphology chooses which one of these Goals eventually defines the feature specification of the Probe. This interaction between the Syntactic component and the Morphological component is schematically represented in (36).

\footnotetext{
${ }^{17} \mathrm{X}$ excludes $\mathrm{Y}$ if no segment of $\mathrm{X}$ dominates $\mathrm{Y}$.

${ }^{18}$ I do not assume the derived notion of dominance (May 1985; Chomsky 1986) in which X dominates Y iff all segments of X dominate Y. Rather, I assume the more primitive notion of domination.

${ }^{19}$ I assume Morphology to be a subcomponent of the PF-branch (cf. Halle and Marantz 1993; Harley and Noyer 1999). At the level of Morphology, feature bundles are replaced with Vocabulary Items. Agreement features are replaced with affixes.
} 
Interaction between the Syntactic and the Morphological component

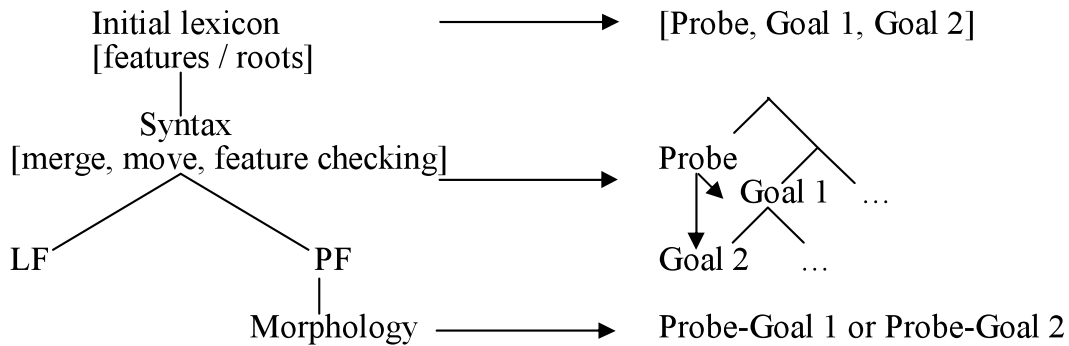

The schematic representation in (36) should be interpreted as follows. The initial lexicon contains the Probe, Goal 1 and Goal 2. The Syntactic component establishes a hierarchical ordering between these three feature bundles. When the derivation is completed, the Probe finds itself in a configuration in which it has two equally local Goals (as indicated by the arrows). The Morphological component has to decide what to do with this configuration. There are several logical possibilities:

(i) Both agreement relations are spelled out, resulting in two affixes on the Probe. Each affix reflects the feature specification of one Goal.

(ii) One of the agreement relations is spelled out, resulting in one affix on the Probe. The feature specification of only one of the two Goals is spelled out on the Probe.

(iii) Both agreement relations are spelled out, resulting in one affix expressing (a subset of) the features of both Goals at the same time.

(iv) None of the agreement relations are spelled out, resulting in either a crashing derivation (Morphology is not able to cope with the situation) or in no agreement affix on the Probe.

I show that when the situation in (32) arises, only one of the two agreement relations is spelled out: Morphology chooses one of the two available Goals to define the agreement morphology on the Probe. If there are two Goals available to a Probe, the Goal that determines the features spelled out on the Probe is not selected randomly. Rather, I show that the relation between the Probe and the Goal that results in the most specific agreement morphology will be spelled out. For the structure in (32), this means that the relation between $\mathrm{C}^{\circ}$ and PhiP takes precedence over that between $\mathrm{C}^{\circ}$ and Participant if the former relation results in more specific morphology on the Probe and vice versa. The question is how 'more specific morphology' should be defined. By assumption there are (at least) two types of affixes in the lexicon containing the Vocabulary Items: those belonging to a specific combination of phi-features and those that are inserted when there is no affix belonging to that specific person/number combination. To the former set of affixes I will refer with the term 'specific affixes', to the latter with the term 'elsewhere affixes'. I assume that specific affixes are 'more specific' than elsewhere affixes. This is represented in example (37).

specific affix $>$ elsewhere affix $>$ no affix

There are two important caveats at this point. First of all, it is not the case that the competition between the affixes when two Goals are available is completely parallel 
to the competition between affixes when only one Goal is available. In the latter case, the Subset Principle (see Halle 1997) defines which affix is more suitable to replace the feature bundle on the Probe, i.e. which feature bundle matches most features of the Probe. In the former case, there are two feature bundles associated with the Probe: each feature bundle is related to a certain Goal. The subset principle chooses the most suitable affix for each of these two relations, resulting in two affixes: each affix matches the features of the relation it replaces best. Only then, when the two most suitable affixes for the two agreement relations with the Probe are found, one of these two affixes has to be inserted on the Probe. I assume that the mechanism responsible for this decision chooses to insert the more specific of the two affixes, i.e. the affix expressing the most features. Secondly, it is not necessarily the case that the Goal with the most specific feature specification defines the feature specification of the Probe in the case that there are two Goals. It is crucially the Goal whose feature specification results in the most specific agreement morphology on the Probe that defines the feature specification on the Probe. For example, suppose there are two Goals, the first is specified first person plural, the second has the specification second person singular. By standard assumptions concerning underspecification, the feature specification of the first Goal is more specific than that of the second Goal. First person is usually regarded more specific than second person and singular is usually seen as the default value for number. When the second Goal leads to a specific affix, whereas the former leads to an elsewhere affix it is the second, less specific Goal, that defines the feature specification of the Probe.

\subsection{Complementizer agreement in Hellendoorn Dutch: Analysis}

Now let us go back to the examples of complementizer agreement in Hellendoorn Dutch. Consider again the examples in (30), repeated here as (38) and the relevant part of the derivation in (32), repeated here as (39).

(38) Ik dèènke darr-e wiej den besten bin-t!

I think that-1P.sG we the best are-elsew

'I think that we are the best!'

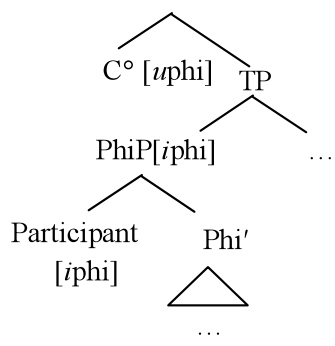

At this point in the derivation Probe $\mathrm{C}^{\circ}$ searches its c-command domain and finds two equally local goals: PhiP and Participant. At the level of Morphology it has to be decided which one of these two Goals determines the agreement affix on the complementizer. Recall that at the end of Sect. 2 I established the feature specification in (14), repeated here as (40), for the affixes in Hellendoorn Dutch. 
(40) $[1 \mathrm{p} . \mathrm{sg}] \quad \rightarrow-e /-0$

$[\mathrm{pl}$, past tense] $\rightarrow-e n$

[elsewhere] $\rightarrow-t$

The only available affix in the CA paradigm is the schwa-affix (see Sect. 2 above for discussion as to why the other affixes are not available on the complementizer). In order for this affix to appear, the complementizer has to agree with a first person singular goal. In the analysis of the pronominal structure provided above there is indeed such a phi-feature set available. The specifier of PhiP, Participant, has the feature specification first person singular. This Goal is local to $\mathrm{C}^{\circ}$ and hence, can value $\mathrm{C}^{\circ}$ 's unvalued phi-features. This means that it is not the relation between $\mathrm{C}^{\circ}$ and PhiP that leads to $\mathrm{CA}$, but rather it is the relation between $\mathrm{C}^{\circ}$ and Participant that results in the presence of a schwa-affix on the complementizer.

This analysis immediately explains the data in example (13), repeated below as (41). In (b), the Participant features are not local enough to the complementizer to trigger $\mathrm{CA}$.

$$
\begin{aligned}
& \text { a. ... darr-e wiej en Marie oonszelf in de spiegel ziet } \\
& \text { that- }{ }_{\text {AGR }}[\text { we and Marie }]_{1 \mathrm{P} . \mathrm{PL}} \text { ourselves in the mirror see } \\
& \text { '... that we and Marie see ourselves in the mirror' } \\
& \text { b. ... * } \text { darr-e/ dat Marie en wiej oonszelf in de spiegel ziet }_{\text {that- }{ }_{\text {AGR }} / \text { that }[\text { Marie and we }]_{1 \mathrm{P} . \mathrm{PL}} \text { ourselves in the mirror see }} \\
& \text { '... that Marie and us see ourselves in the mirror' }
\end{aligned}
$$

Consider the relevant part of the derivation of the example in (41a) in

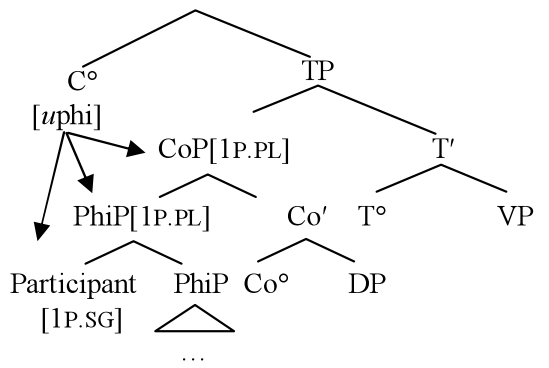

Probe $\mathrm{C}^{\circ}$ is merged with TP. The subject occupies the specifier of TP. The subject in this example is a coordination of a first person plural pronoun and a third person singular proper name. The feature specification of the coordinated subject as a whole is first person plural, as shown by the feature specification of the reflexive pronoun oonszelf 'ourselves'. The first conjunct of the coordinated subject also has the feature specification [1p.pl]. This first person plural pronoun is internally complex. It contains a specifier hosting the Participant features which are first person singular. Probe $\mathrm{C}^{\circ}$ encounters three equally local Goals in this configuration: $\mathrm{CoP}$ is equally local to $\mathrm{C}^{\circ}$ as its specifier, PhiP, which in turn is equally local to $\mathrm{C}^{\circ}$ as its own specifier, Participant. At the level of Morphology, the feature specification of one of these Goals has to be spelled out as an agreement affix on the complementizer. As 
I have shown above, there is only one affix available to appear on the complementizer, namely the schwa-affix. This affix has the feature specification [1p.sg]. This means that the agreement relation between $\mathrm{C}^{\circ}$ and $\mathrm{CoP}$, and the one between $\mathrm{C}^{\circ}$ and PhiP do not lead to an agreement affix on the complementizer, whereas the agreement relation between $\mathrm{C}^{\circ}$ and Participant does lead to overt agreement morphology on the complementizer. The schwa-ending on the complementizer in the example in (41a) represents the agreement relation between $\mathrm{C}^{\circ}$ and the Goal that is most deeply embedded.

At this point it is also clear why the example in (41b) is ungrammatical. The first conjunct of the coordinated subject does not contain the internally complex plural pronoun in this case, but the proper name, Marie. The pronoun containing the first person singular Goal constitutes the second conjunct of the coordinated subject. However, this Goal is not local enough to $\mathrm{C}^{\circ}$ to enter into a relation with the complementizer and hence the schwa-affix cannot occur.

\subsection{Verbal agreement in Hellendoorn Dutch}

I have argued in the preceding subsection that the agreement on the complementizer in Hellendoorn Dutch is a reflex of the agreement relation between $\mathrm{C}^{\circ}$ and Participant. This subsection provides an analysis for the absence of this schwa-affix on the finite verb in SVO and CSOV clauses in this dialect. First consider the ungrammatical example in (43).

\section{*Wiej binn-e den besten! we $_{1 P . P L}$ are-1P.SG the best}

This example shows that the finite verb cannot be inflected with a schwa-affix in the SVO order when it agrees with a first person plural subject pronoun. The schwaending has been argued to reflect first person singular features. I follow the standard assumption that the agreement morphology on the finite verb in SVO and CSOV clauses in Dutch spells out the agreement relations of Probe $\mathrm{T}^{\circ}$ (cf. among others, Zwart 1993, 1997). Consider the structure in (44), representing the stage of the derivation in which Probe $\mathrm{T}^{\circ}$ is merged into the structure.

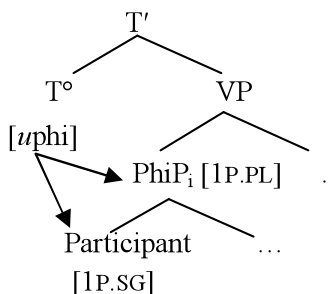

At the stage of the derivation represented in (44), $\mathrm{T}^{\circ}$ is merged with VP. The c-command domain of $\mathrm{T}^{\circ}$ contains a first person plural subject pronoun. The pronominal projection contains two equally local Goals with respect to $\mathrm{T}^{\circ}$ : $\mathrm{PhiP}$ and Participant. Up until this stage of the derivation, the agreement relations $\mathrm{T}^{\circ}$ entertains are completely parallel to the agreement relations $\mathrm{C}^{\circ}$ entertains in the structure in (39). The difference, however, between $\mathrm{T}^{\circ}$ and $\mathrm{C}^{\circ}$ in Dutch is that $\mathrm{T}^{\circ}$ has 
an EPP feature: it attracts the subject to its specifier position. If we assume, following Chomsky $(1995,2000)$, that Move is a combination of the operations Agree and Merge, it becomes clear why agreement with Participant is prohibited when $\mathrm{T}^{\circ}$ has an EPP-feature. If $\mathrm{T}^{\circ}$ agrees with Participant, it also attracts Participant to its specifier position. As Participant is the specifier of the subject this leads to a violation of the subject island condition and/or the left-branch condition (Ross 1967; Huang 1982). ${ }^{20}$ The difference between the derivation in (39) with $\mathrm{C}^{\circ}$ as Probe and the one in (44) with $\mathrm{T}^{\circ}$ as Probe can now be described as follows. $\mathrm{C}^{\circ}$ in (39) encounters the equally local Goals PhiP and Participant simultaneously. Morphology determines which Goal will specify the agreement affix on the Probe. Probe $\mathrm{T}^{\circ}$ in (44) also encounters these two Goals Participant and PhiP simultaneously. However, one of the relations is discarded in this case because the Agree-relation feeds a movement operation. As a consequence, the only relation that is available, i.e. the relation between $\mathrm{T}^{\circ}$ and PhiP, has to be spelled out as agreement morphology on the finite verb (cf. Soltan 2007 for a similar analysis of the unavailability of First Conjunct Agreement under movement). This relation does not result in the specific schwa-affix on the finite verb, but in the elsewhere $t$-affix, as is shown in example (45).

$$
\begin{aligned}
& \text { Wiej bin-t den besten! } \\
& \text { we }_{1 P . P L} \text { are-ELSEW the best } \\
& \text { 'We are the best!' }
\end{aligned}
$$

The verb in finite main clauses, like the one in example (45), moves further to $\mathrm{C}^{\circ}$ in Verb Second languages like Dutch (cf. among others, den Besten 1989). ${ }^{21} \mathrm{C}^{\circ}$ also has phi-features in this dialect, however, these phi-features do not have an effect in this case as $\mathrm{C}^{\circ}$ also has an EPP-feature attracting the subject to Spec,CP. This analysis of verbal agreement in SVO and CSOV clauses predicts that CA in Hellendoorn Dutch should be impossible if the subject moves out of the c-command domain of $\mathrm{C}^{\circ}$. In Sect. 5 below I discuss this prediction in detail and I show that it is borne out by the data.

Now consider again the example in (9), repeated here as (46).

a. *Bin-t wiej den besten? are-AGR we the best

b. Binn-e wiej den besten? are-AGR we the best

'Are we the best?'

\footnotetext{
${ }^{20}$ An anonymous $N L L T$ reviewer notes that in sentence like which boy is swimming the whole subject which boy can be pied-piped whereas only the wh-feature of which is targeted for Agree and hence movement. If this is indeed the case the question arises why in the case discussed in the main text, the whole subject cannot be pied-piped when just the features of the participant are targeted for agreement and hence for movement. I have no full-fledged answer to this question, but one might consider that the $w h$-feature percolates to the maximal projection. So it might be that in this case the Agree relation is with DP, rather than with Spec,DP. Although the Participant features also move to the maximal projection, these features will be unified with the individuation features and are hence no longer independently accessible.

${ }^{21}$ Zwart $(1993,1997)$ proposes an alternative analysis in which the finite verb moves only as far as $I^{\circ}$ in subject-initial main clauses, and to $\mathrm{C}^{\circ}$ in inverted main clauses. This analysis is also compatible with the analysis proposed in this paper (cf. van Koppen 2005 for an elaboration).
} 
In this example the finite verb precedes the subject and obligatorily carries the schwaaffix. Just like in example (45) above, $\mathrm{T}^{\circ}$ can only agree with the subject as a whole, because it carries an EPP-feature. However, in this case $\mathrm{C}^{\circ}$ does not attract the subject to its specifier and hence does not have an EPP-feature. This means that the phifeatures of $\mathrm{C}^{\circ}$ can be related to both the pronoun as a whole and the Goal internal to the pronominal structure. Consider the analysis of these examples in (47).

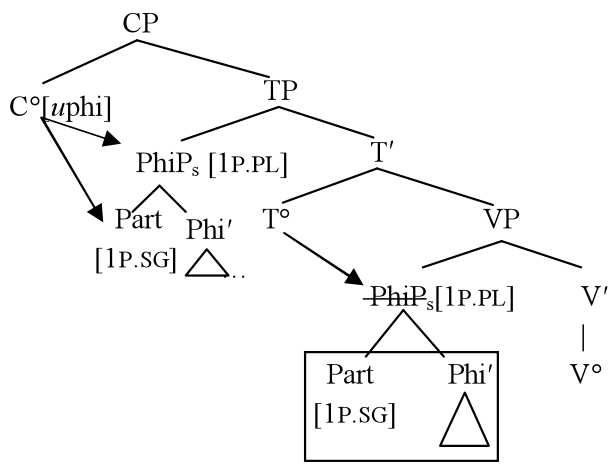

The derivation of the example in (46b) proceeds as follows. $\mathrm{T}^{\circ}$ is merged with VP. It has unvalued phi-features and an EPP-feature. It searches its c-command domain and finds two equally local Goals, PhiP and Participant. $\mathrm{T}^{\circ}$ cannot Agree with Participant, however, for the reasons provided above. As a consequence the only Goal for Probe $\mathrm{T}^{\circ}$ is PhiP. The subject moves to Spec,TP and then $\mathrm{C}^{\circ}$ is merged. $\mathrm{C}^{\circ}$, on a par with $\mathrm{T}^{\circ}$, has unvalued phi-features as Hellendoorn Dutch is a dialect with CA. The c-command domain of $\mathrm{C}^{\circ}$ contains two equally local Goals: PhiP and Participant (represented as Part in the configuration in (47). $\mathrm{C}^{\circ}$ does not have an EPP-feature in this case. Hence, there is nothing prohibiting $\mathrm{C}^{\circ}$ to enter into an agreement relation with both these Goals. As a result the agreement relation between $\mathrm{C}^{\circ}$ and Participant can be established and the schwa-affix can be spelled out on the finite verb.

\subsection{Summary}

This section has provided the main empirical argument for the idea that the Participant features of PhiP form a discrete valued phi-feature set which is accessible to the syntactic operation Agree. I have shown that the complex distribution of the $e$-affix in the DA dialects, like Hellendoorn Dutch, can be accounted for if we assume that the first person plural pronouns contain a left-peripheral, discrete set of first person singular Participant features.

\section{Arguments in favor of the analysis}

This section discusses two arguments in favor of the analysis provided in Sect. 4. First, CA in dialects with the DA pattern is compared to dialects with regular CA. I show that in the latter dialects, the complementizer agrees with PhiP rather than with the Participant features in the left periphery of the pronominal projection. This 
structural difference accounts for the distributional variation concerning CA in DA dialects and in the regular dialects without a DA pattern.

Secondly, I discuss (partial) agreement with coordinated subjects in Dutch dialects. I show that CA with the first conjunct of a coordinated subject, which arguably also occupies the highest specifier position in the left periphery, displays the same patterns as agreement with Participant features in the left periphery of the pronominal projection in Hellendoorn Dutch. This shows that the analysis developed in the previous section is also applicable to other empirical domains. The similarity between these distribution patterns also provides an argument in favor of the idea that the Participant features in pronouns occupy the highest specifier position in the left periphery of the pronominal projection.

\subsection{Two types of Complementizer Agreement}

This subsection compares CA in a DA dialect like Hellendoorn Dutch with regular CA in Tegelen Dutch. As I have shown in Sect. 2 above, Hellendoorn Dutch CA and Tegelen Dutch CA each represent a different type of CA dialect. Hellendoorn Dutch CA is sensitive to modification and extraction of the subject, whereas CA in Tegelen Dutch is not. This section shows that this dissimilarity can be reduced to the following syntactic difference: Hellendoorn Dutch CA reflects the agreement relation between $\mathrm{C}^{\circ}$ and Participant, whereas Tegelen Dutch regular CA spells out the relation between $\mathrm{C}^{\circ}$ and PhiP. Consider the configuration in (48).

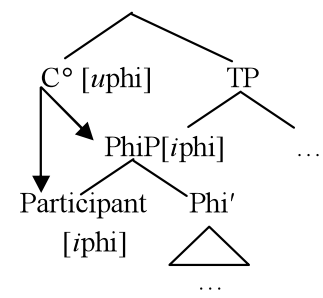

Before I show how this syntactic difference can account for the variation with respect to CA in Tegelen Dutch and Hellendoorn Dutch, I first discuss CA in Tegelen Dutch.

The complementizer in Tegelen Dutch agrees with second person singular subjects. This is illustrated in (49).

$$
\begin{aligned}
& \text { Ich dink de-s doow morge kum-s. } \\
& \text { I think that-2P.SG you 2P.SG tomorrow come-2P.SG } \\
& \text { 'I think that you will come tomorrow.' }
\end{aligned}
$$

The complementizer det 'that' is inflected with an $s$-affix. This affix represents the agreement relation between $\mathrm{C}^{\circ}$ and the second person singular subject doow ' $\mathrm{you}_{\mathrm{sg}}$ ' This variety of Dutch does not show agreement on the complementizer for any other person/number combination. Consider the table in (50), representing both the CA paradigm of this dialect and the present and past tense paradigm of the verb gaan 'to go'. 


\begin{tabular}{|l|l|l|l|}
\hline & CA & $\begin{array}{c}\text { Present } \\
\text { Tense }\end{array}$ & Past Tense \\
\hline 1P.SG & det & goan & ging \\
\hline 2P.SG & de-s & gei-s & ging-s \\
\hline 3P.SG & det & gei-t & ging \\
\hline 1P.PL & det & goan & ging-e \\
\hline 2P.PL & det & goa- $t$ & gingk \\
\hline 3P.PL & det & goan & ging-e \\
\hline
\end{tabular}

This table shows that the agreement ending in the present and the past tense are the same in the second person singular and not in any other person/number combination. As discussed above in Sect. 2, this means that the complementizer only agrees with second person singular subjects. In light of the discussion of CA in Hellendoorn Dutch, the question can be raised how the examples in (2) should be analyzed: which agreement relation does the inflectional morphology on the complementizer in these two dialects reflect? As Tegelen Dutch only shows CA with second person singular subjects, the affix insertion rules for CA in this dialect can simply be represented as in $(51) .^{22}$

$$
[2 \mathrm{P} . \mathrm{SG}] \rightarrow-s
$$

The feature specification of Participant of this subject pronoun, on a par with that of the second person plural subject pronoun, is specified just for second person and not for number (see the discussion in Sect. 4 above). In other words, in Tegelen Dutch there appears to be an affix with the feature specification second person singular, but there is no affix associated with the CA paradigm with the feature specification second person. As such we have to conclude that in Tegelen Dutch it is the relation between $\mathrm{C}^{\circ}$ and $\mathrm{PhiP}$ that is spelled out as an agreement affix on the complementizer.

\subsubsection{Modification of the subject}

$\mathrm{CA}$ in Hellendoorn Dutch reflects the agreement relation between $\mathrm{C}^{\circ}$ and Participant. This analysis makes the prediction that when the specifier containing the Participant features is less local to $\mathrm{C}^{\circ}$ than $\mathrm{PhiP}, \mathrm{C}^{\circ}$ can no longer enter into an agreement relation with Participant. In this case, $\mathrm{C}^{\circ}$ only agrees with PhiP. As this relation does not result in overt agreement morphology, the complementizer is not expected to show agreement. In other words, when Participant is not equally local to $\mathrm{C}^{\circ}$ as PhiP, the complementizer is expected to remain uninflected. When Participant is less local to $\mathrm{C}^{\circ}$ than PhiP in Tegelen Dutch, this is not expected to have an influence on the presence of CA. In these varieties, CA spells out the relation between $\mathrm{C}^{\circ}$ and PhiP. As a consequence, the locality of Participant with respect to $\mathrm{C}^{\circ}$ is not expected to have an influence on CA in these varieties. In this subsection, I demonstrate that when the pronominal projection is modified by a focus particle (like zelfs 'even' or ook 'also'), the situation arises in which Participant is no longer equally local to $\mathrm{C}^{\circ}$ as PhiP.

\footnotetext{
${ }^{22}$ The other logically feasible feature specification for the $s$-affix is [2p]. However, it would then also be expected to appear on the complementizer with second person plural subjects. This is not the case, however.
} 
I show that when a subject pronoun is modified in Tegelen Dutch, this does not have an effect on the presence of CA, whereas if it is modified in Hellendoorn Dutch, it does have an effect. Consider the structure in (52).

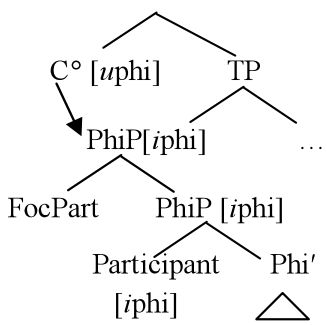

A focus particle modifies the pronoun in this structure. This focus particle is adjoined to the pronominal projection. ${ }^{23} \mathrm{C}^{\circ}$ is merged with the structure containing the modified pronominal projection. $\mathrm{C}^{\circ}$ has unvalued phi-features and hence is a Probe. It searches its c-command domain for matching Goals, but as the pronominal projection contains an adjunct, it encounters just one local Goal, namely PhiP. Participant is not equally local to $\mathrm{C}^{\circ}$ as PhiP in this configuration, as it is not only c-commanded by $\mathrm{C}^{\circ}$, but also by the focus particle occupying the highest specifier of the pronominal projection. Consider again the relevant definitions concerning locality and ccommand in (33), (34), and (35). The focus particle c-commands Participant, as (i) the focus particle excludes Participant and (ii) the first node that dominates the focus particle, PhiP, also dominates Participant. The maximal projection of the pronominal projection is c-commanded by $\mathrm{C}^{\circ}$ and by $\mathrm{C}^{\circ}$ alone. Participant on the other hand is c-commanded by both $\mathrm{C}^{\circ}$ and the focus particle. This means that the set of nodes c-commanding PhiP is a proper subset of the set of nodes c-commanding Participant. As a consequence, $\mathrm{PhiP}$ is more local to $\mathrm{C}^{\circ}$ than Participant.

$\mathrm{CA}$ in Hellendoorn Dutch reflects the features of the agreement relation between $\mathrm{C}^{\circ}$ and Participant. Given the reasoning provided above, $\mathrm{CA}$ is predicted to be impossible in this situation. This prediction is borne out by the data in (53).

$$
\begin{aligned}
& \text { a. ... dat zölfs wiej de wedstrijd wint } \\
& \text { that even we the game win } \\
& \text { '... that we even win the game' } \\
& \text { b. ... * *darr-e zölfs wiej de wedstrijd wint } \\
& \text { that-1P.sG even we the game win }
\end{aligned}
$$

These examples show that when the first person plural subject in Hellendoorn Dutch is modified by a focus particle, the complementizer has to appear in its bare, uninflected form, as predicted.

\footnotetext{
${ }^{23}$ For argumentation in favor of the claim that focus particles are adjuncts, rather than projecting their own category, cf. Barbiers (1995: 71). Furthermore, I refer the reader to Barbiers (2003) for argumentation in support of the idea that focus particles are adjuncts attached to the projection they are modifying, rather than being clausal adverbs as claimed by among others, Büring and Hartmann (2001).
} 
The agreement morphology on the complementizer in Tegelen Dutch reflects the agreement relation between $\mathrm{C}^{\circ}$ and PhiP (and not the one between $\mathrm{C}^{\circ}$ and Participant). This means that a configuration in which Participant is not equally local to $\mathrm{C}^{\circ}$ as PhiP is not expected to have an influence on the presence of CA. This expectation is borne out by the data in (54).

$$
\begin{aligned}
& \ldots \text { de-s/ }{ }^{*} \text { ?det auch doow merge kum-s } \\
& \text { that-2P.SG } / \text { that also you }{ }_{\mathrm{SG}} \text { tomorrow come-2P.SG } \\
& \text { '... that you too will come tomorrow' }
\end{aligned}
$$

These data show that in Tegelen Dutch, the presence of CA is not blocked by modification of the subject pronoun.

To summarize, the analysis of CA in Hellendoorn Dutch on the one hand and in Tegelen Dutch on the other differs in one crucial aspect. The agreement on the complementizer in Hellendoorn Dutch reflects the agreement relation between $\mathrm{C}^{\circ}$ and Participant, whereas CA in Tegelen Dutch spells out the relation between $\mathrm{C}^{\circ}$ and PhiP. This difference makes a clear prediction concerning the configuration in which the subject pronoun is modified by a focus particle. The effect of this focus particle is that Participant is no longer equally local to Probe $\mathrm{C}^{\circ}$ as PhiP. This results in the absence of CA in dialects like Hellendoorn Dutch. However, it does not have an influence on the presence of CA in dialects like Tegelen Dutch.

\subsubsection{Extraction}

As shown in Sect. 4, movement of subject pronoun past the Probe has an effect on the agreement morphology of this Probe in the sense that it cannot Agree with Goals internal to this subject pronoun. I argued that the reason for this is that Probes with an EPP-feature can only target Goals that are actually allowed to undergo Move, as Move is a combination of the operations Agree and Merge. The Goals internal to the subject pronoun cannot be the target of Agree and hence Move in this case, since this would lead to a subject island violation.

Now, recall the difference between the analysis of CA in Hellendoorn Dutch and Tegelen Dutch. CA spells out the relation between $\mathrm{C}^{\circ}$ and Participant in Hellendoorn Dutch, whereas it spells out the relation between $\mathrm{C}^{\circ}$ and PhiP in Tegelen Dutch. Given the reasoning above, the relation between $\mathrm{C}^{\circ}$ and Participant cannot be spelled out when the subject moves out of the c-command domain of $\mathrm{C}^{\circ}$. This means that extraction of the subject in Hellendoorn Dutch leads to an uninflected complementizer. Extraction of the pronominal subject in Tegelen Dutch does not have this effect, as in this dialect the agreement on the complementizer reflects the agreement relation with PhiP. The features of this Goal are still available to $\mathrm{C}^{\circ}$ after movement of the subject.

These predictions are confirmed by the data. First consider the Hellendoorn Dutch example in (55) (from van Craenenbroeck and van Koppen 2002) and its derivation in (56).

(55) WIEJ denkt Jan dat/ *darr-e die pries ewönnen hebt, nie ZIEJ. we think Jan that/ that-1P.sG that prize won have not they 'WE John thinks won that prize, not THEY.' 
(56)

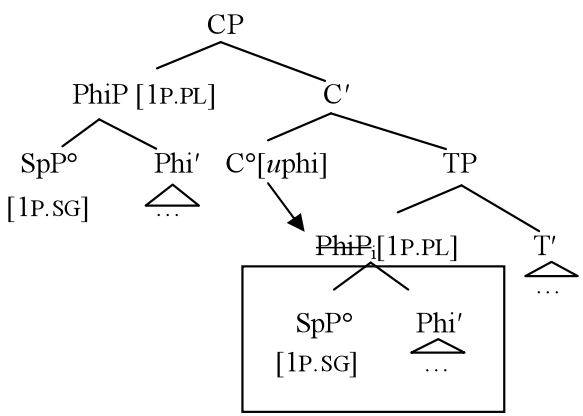

$\mathrm{C}^{\circ}$ in (56) has both unvalued phi-features and an EPP-feature. As a consequence, $\mathrm{C}^{\circ}$ cannot Agree with Participant as that would result in movement of Participant to Spec,CP, and hence in a subject island violation. This means that the only relation that can be established is the one between $\mathrm{C}^{\circ}$ and PhiP. This relation does not lead to agreement morphology on the complementizer in this dialect.

Extraction of the subject in Tegelen Dutch has no effect on the presence of CA. This is expected as this variety shows agreement with PhiP rather than with a PhiPinternal Goal. Consider the examples in (57) (for similar data from Frisian, cf. de Haan 1997; and for similar data from Bavarian, cf. Bayer 1984).

$$
\begin{aligned}
& \text { DOOW denk ik de-s/ *det de wedstrijd winnen zal-s. } \\
& \text { you }_{\mathrm{SG}} \text { think I that-2P.sG } / \text { that the game win will-2P.SG } \\
& \text { 'YOU, I think will win the game.' }
\end{aligned}
$$

\subsubsection{Summary}

There are two types of CA in Dutch dialects. The first type reflects Agree with a Goal internal to PhiP (the Hellendoorn type), the second type Agree with PhiP itself (the Tegelen type). These two types of CA differ with respect to modification and movement. If the pronoun in the Hellendoorn type of CA is extracted or modified, CA can no longer occur. However, if the pronoun in the Tegelen type of CA is extracted or modified, there is no effect on CA. These data confirm the conclusion drawn in the previous section that the phi-features on $\mathrm{C}^{\circ}$ in Hellendoorn Dutch target the left peripheral Participant features of the first person plural pronoun.

\subsection{Agreement with coordinated subjects}

This subsection draws a parallel between DA in Hellendoorn Dutch and CA with coordinated subjects in Tegelen Dutch. I show that the assumptions I have made to account for the DA pattern in Dutch dialects can also account for agreement with coordinated subjects in Dutch dialects. But, more importantly, I show that the distribution of CA with the first conjunct of a coordinated subject is parallel to the distribution of CA in Hellendoorn Dutch. This is expected since in both cases we are dealing 
with agreement between $\mathrm{C}^{\circ}$ and a Goal situated in the left periphery of the subject. First consider the data in (58).

$$
\begin{aligned}
& \text { a. ... de-s doow en ich ôs kenn-e treffe Tegelen Dutch } \\
& \text { that- } 2 \text { sg }\left[\text { you }_{\mathrm{SG}} \text { and } \mathrm{I}\right]_{1 \mathrm{PL}} \text { each.other }{ }_{1 \mathrm{PL}} \text { can- }{ }_{\mathrm{PL}} \text { meet } \\
& \text { '... that you and I can meet' } \\
& \text { b. ... da-n Bart en Jan mekaar wel kunn-e verdraagn } \\
& \text { that-PL }[\text { Bart and Jan }]_{3 \mathrm{PL}} \text { each.other part can- }{ }^{\mathrm{PL}} \text { stand } \\
& \text { '... that Bart and Jan tolerate each other' Nieuwkerken-Waas Dutch }
\end{aligned}
$$

These examples show that in Dutch dialects that display CA, CA can spell out either the relation between $\mathrm{C}^{\circ}$ and the coordinated subject as a whole, as in (58b), or the relation between $\mathrm{C}^{\circ}$ and the first conjunct of a coordinated subject, as in (58a). Whether agreement is with the maximal projection of the coordination phrase, resulting in agreement with the coordinated subject as a whole, or with the first conjunct, resulting in first conjunct agreement, is dependent on the same morphological mechanism that I have argued for the two types of CA and the DA patterns discussed above. ${ }^{24}$ This subsection is organized as follows. I first discuss agreement on the complementizer with the first conjunct in Tegelen Dutch. I show that this instance of CA has the same properties as DA in Hellendoorn Dutch, as in both cases CA spells out the relation between $\mathrm{C}^{\circ}$ and a Goal in the left periphery of the subject. The second subsection discusses CA with the coordination as a whole. This instance of CA reflects an agreement relation between $\mathrm{C}^{\circ}$ and the maximal projection of the subject and hence should behave similar to second type of CA identified in Sect. 3, namely CA with PhiP in Tegelen Dutch.

\subsubsection{Tegelen Dutch}

Consider the example in (59)

$$
\begin{aligned}
& \ldots \text { de-s doow en ich ôs treff-e } \\
& \text { that-2P.SG }\left[\text { you }_{\text {sg }} \text { and I }\right]_{1 \text { P.PL }} \text { each.other }{ }_{1 P . P L} \text { meet-PL } \\
& \text { '... that you and I could meet' }
\end{aligned}
$$

The coordinated subject in this example is first person plural, as becomes clear if we look at the feature specification of the reciprocal $\hat{o} s$ 'each other' (lit. 'us'), which is also first person plural. Furthermore, the finite verb treffe 'meet' carries plural morphology. The complementizer, showing second person singular agreement, does not agree with the subject coordination as a whole, but with its first conjunct. I propose the following analysis for this example (cf. Van Koppen 2005, 2008 for elaboration).

\footnotetext{
${ }^{24}$ In van Koppen (2005, 2008), I also discuss an extension of this analysis to agreement with coordinated subjects in Irish and Arabic and so-called Long Distance Agreement in Tsez.
} 
(60)

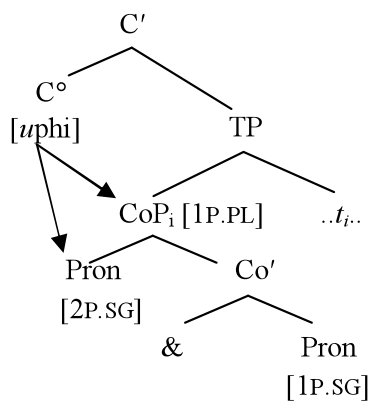

I assume that coordinations are organized in CoPs following, among others Kayne (1994), Johannessen (1998), and Progovac (1998). ${ }^{25}$ Tegelen Dutch is a dialect with $\mathrm{CA}$, which means that $\mathrm{C}^{\circ}$ has unvalued phi-features (cf. infra Sect. 3.2.1). These features have to be valued. Agree searches $\mathrm{C}^{\circ}$ 's c-command domain for a suitable Goal. Agree finds two potential Goals: CoP (hosting the unified/merged feature set of the features in the first and the second conjunct, see Sect. 3.3 above) and the pronoun in [SpecCoP]. These Goals are equally local according to the definitions provided in (33), (34), and (35) above. At the level of Morphology one of these relations has to be spelled out. To see which relation results in the more specific agreement morphology, consider the CA paradigm of this dialect in the table in (61).

\begin{tabular}{|c|c|}
\hline $\begin{array}{c}\text { Feature specification } \\
\text { subject }\end{array}$ & $\begin{array}{c}\text { Form of the } \\
\text { complementizer }\end{array}$ \\
\hline 1P.SG & det \\
\hline 2P.SG & de-s \\
\hline 3P.SG & det \\
\hline 1P.PL & det \\
\hline 2P.PL & det \\
\hline 3P.PL & det \\
\hline
\end{tabular}

Either the relation between $\mathrm{C}^{\circ}$ and a second person singular first conjunct, or the relation between $\mathrm{C}^{\circ}$ and the unified first person plural $\mathrm{CoP}$ has to be spelled out on the complementizer. The former relation leads to a specific agreement morpheme on the complementizer, namely the $s$-ending, whereas the latter does not lead to an agreement ending at all. In this case, Morphology spells out the relation between $\mathrm{C}^{\circ}$ and the first conjunct of the coordinated subject, resulting in First Conjunct Agreement (henceforth FCA) on the complementizer as this relation leads to more specific agreement morphology than the other available relation. This analysis of FCA resembles the syntactic analysis of CA in Hellendoorn Dutch: in both cases the relation between $\mathrm{C}^{\circ}$ and a Goal in the specifier position of the subject is realized on the complementizer. If these two cases of CA

\footnotetext{
25 van Koppen (2005) shows that the coordinated subject in the Dutch dialects under discussion cannot have been derived from sentence coordination and concomitant conjunction reduction, as has been argued by Aoun, Benmamoun, and Sportiche (1994) for Arabic, since the predicate can be a reciprocal or a verb which needs a plural subject.
} 
are indeed as similar as the current analysis implies, we expect that the distribution of CA in Hellendoorn Dutch and FCA in Tegelen Dutch is also comparable.

First let us consider modification of the subject. In Hellendoorn Dutch, the complementizer cannot be inflected when the subject is modified by a focus particle like also or too. Also for FCA in Tegelen Dutch the prediction is that if the maximal projection of the subject, i.e. CoP, is modified, the Agree relation with the first conjunct is no longer available since the first conjunct is no longer equally local to $\mathrm{C}^{\circ}$ as $\mathrm{CoP}$. Consider the example in (62).

$$
\begin{aligned}
& \text {... det/ ' de-s auch doow en Anna komm-e } \\
& \text { that/ that-2P.sg also [you sg and Anna] come-pl } \\
& \text { '... that you and Anna will also be coming' }
\end{aligned}
$$

The prediction is not completely borne out by the data. However, two things have to be noted about this example. First of all, both the complementizer with CA and the complementizer without $\mathrm{CA}$ are possible in this example. This is remarkable as in example (54) and example (63), without inflection, the variant with the uninflected complementizer is sharply ungrammatical. So apparently, modification has an effect on CA.

$$
\begin{aligned}
& \text {... de-s/ *det doow en ich ôs treff-e } \\
& \text { that-2P.SG } / \text { that }\left[\mathrm{you}_{\mathrm{SG}} \text { and }\right]_{1 \mathrm{P} . \mathrm{PL}} \text { each.other }{ }_{1 \mathrm{P} . \mathrm{PL}} \text { meet-PL } \\
& \text { '... that you and I will meet each other' }
\end{aligned}
$$

Secondly, it is not entirely clear what auch 'also' modifies: CoP or Spec,CoP. When it modifies CoP, the focus particle c-commands the specifier of CoP. If, on the other hand, the focus particle modifies just the first conjunct, then the first conjunct is still equally local to $\mathrm{C}^{\circ}$ as $\mathrm{CoP}$, and hence the agreement morphology on the complementizer can reflect the agreement relation between $\mathrm{C}^{\circ}$ and this first conjunct. The latter configuration is reflected in the structure in (64).

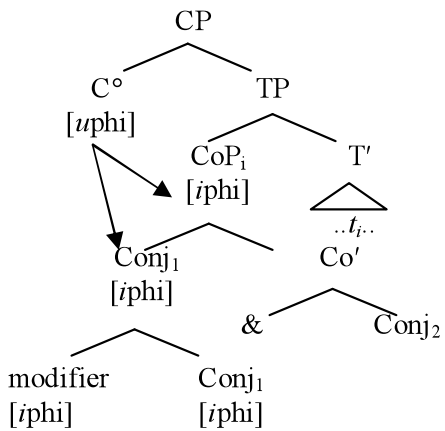

The most natural interpretation is the one in which the focus particle modifies the coordinated subject as a whole, potentially explaining why the variant with the inflected complementizer is degraded. ${ }^{26}$

\footnotetext{
${ }^{26}$ Marcel den Dikken suggested that it would be possible to set up a context in which the focus particle unequivocally targets the first conjunct or the complete coordination. I have tried this with one of my
} 
Secondly, CA in Hellendoorn Dutch is affected by movement of the subject. If the subject is moved out of the embedded clause, CA is no longer possible. Again, the same prediction holds for FCA in Tegelen Dutch: if the coordination moves out of the c-command domain of $\mathrm{C}^{\circ}$, Agree with the first conjunct should be unavailable. The reason for this is also the same as with CA in Hellendoorn Dutch, Agree with the first conjunct leads to Move of the first conjunct if the Probe has an EPP-feature. In this case this would result in a CSC violation (cf. also Soltan 2007). This prediction is borne out by the data, see (65).

$$
\begin{aligned}
& \text { Doow en Marie denk ik, } \\
& \text { [you } \mathrm{sg} \text { and Marie] think I } \\
& \text { a. ... *de-s het spel zull-e winnen. } \\
& \text { that-2P.sG the game will-pL win } \\
& \text { b. ... ? } \begin{array}{l}
\text { det het spel zull-e winnen. } \\
\text { that the game will-pl win }
\end{array}
\end{aligned}
$$

\subsubsection{Nieuwkerken-Waas Dutch}

The complementizer in Nieuwkerken-Waas Dutch agrees with the coordination as a whole, rather than with the first conjunct as in Tegelen Dutch. This subsection shows that the same syntactic configuration underlies $\mathrm{CA}$ with the coordination as a whole in Nieuwkerken-Waas Dutch as underlies First Conjunct Agreement in Tegelen Dutch discussed above. The difference between these two dialects, however, lies at the level of Morphology. The morphological component in Nieuwkerken-Waas Dutch spells out the relation with $\mathrm{CoP}$, whereas it spells out the relation with [SpecCoP] in Tegelen Dutch. First consider again the example from Nieuwkerken-Waas Dutch in (58b), repeated here as (66).

$$
\begin{aligned}
& \text {... da-n Bart en Jan mekaar wel kunn-e verdraagn } \\
& \text { that-PL }[\text { Bart and Jan }]_{3 \mathrm{PL}} \text { each.other PART can-PL stand } \\
& \text { '... that Bart and Jan tolerate each other' }
\end{aligned}
$$

informants and the results are very subtle, yet very promising. Consider the sentences in (i) and (ii). The context in (i) forces the focus particle to go with the first conjunct, whereas the context in (ii) forces it to go with the complete coordination. Confronted with these examples the informant states that he prefers complementizer agreement in the (i) context, but not in the (ii) context, as is expected by the analysis.

(i) A: Danst Marie alleen met Kees? dances Marie only with Kees

'Does Marie dance with just Kees?'

B: Ik denk dat [ook jij] en Marie moeten dansen!

I think that [also you] and Marie should dance

'I think that YOU and Mary should also dance!'

(ii) A: Dansen alleen Piet en Marie?

dance only Piet and Marie

'Do only Piet and Marie dance?'

B: Ik denk dat [ook jij en Ria] moeten dansen!

I think that [also you and Ria] should dance

'I think that Ria and you should also dance!' 
The complementizer in (66) shows third person plural agreement, thus matching the feature specification of the coordinated subject as a whole. The inflection is obligatory. This suggests that the complementizer has to agree with the coordinated subject as a whole (and cannot for instance choose to agree with the first conjunct). Consider the relevant part of the derivation of the example (66) in the tree structure in (67).

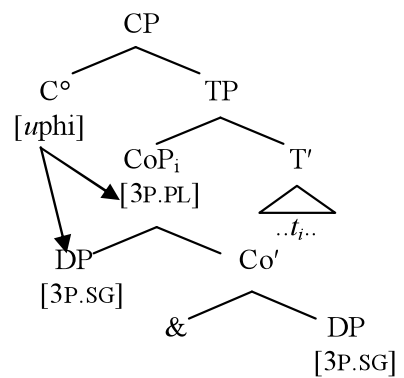

This derivation runs parallel to the one discussed above for Tegelen Dutch. The subject is merged with $\mathrm{T}^{\circ}$, after which $\mathrm{C}^{\circ}$ is merged. $\mathrm{C}^{\circ}$ has unvalued phi-features, as Nieuwkerken-Waas Dutch is a dialect with $\mathrm{CA}$. This means that $\mathrm{C}^{\circ}$ is a Probe, and Agree searches its c-command domain for a suitable Goal. Just as in Tegelen Dutch, $\mathrm{CoP}$ and the Goal in $[\mathrm{SpecCoP}]$ are equally local with respect to $\mathrm{C}^{\circ} \cdot \mathrm{C}^{\circ}$ enters into a relation with both these possible Goals. At the level of Morphology, it has to be decided which one of the two available relations gets spelled out on the complementizer. According to the assumptions made in the first chapter, the relation resulting in the more specific agreement morphology is spelled out. Consider the paradigm of agreement morphology on the complementizer in Nieuwkerken-Waas Dutch in (68).

\begin{tabular}{|c|c|}
\hline $\begin{array}{c}\text { Feature specification } \\
\text { subject }\end{array}$ & $\begin{array}{c}\text { Form of the } \\
\text { complementizer }\end{array}$ \\
\hline 1P.SG & $d a-n$ \\
\hline 2P.SG & $d a$ \\
\hline 3P.SG & $d a$ \\
\hline 1P.PL & $d a-n$ \\
\hline 2P.PL & $d a$ \\
\hline 3P.PL & $d a-n$ \\
\hline \multicolumn{2}{|l}{} \\
\hline
\end{tabular}

There are two potential agreement relations to be spelled out: the one with the [3pl]features of $\mathrm{CoP}$ or the relation with the [3sg]-features of the first conjunct. Only the former feature specification results in an (overt) agreement affix on the Probe. As a consequence, at the level of Morphology it is this more specific affix which is selected. The difference between Nieuwkerken-Waas Dutch and Tegelen Dutch hence boils down to a difference in affix inventories, i.e. a difference in the lexicon. In Nieuwkerken-Waas Dutch, the relation between $\mathrm{C}^{\circ}$ and $\mathrm{CoP}$ leads to the most specific agreement affix, whereas in Tegelen Dutch it is the relation between $\mathrm{C}^{\circ}$ and the specifier of CoP. This analysis of the difference between Tegelen Dutch and Nieuwkerken-Waas Dutch predicts that First Conjunct agreement in NieuwkerkenWaas Dutch should in principle be able to occur, namely when the relation between 
$\mathrm{C}^{\circ}$ and $\mathrm{Spec}, \mathrm{CoP}$ results in more specific agreement morphology than that between $\mathrm{C}^{\circ}$ and CoP. This is exactly what happens in example (69). ${ }^{27}$

(69) ... ? da-n ze.zulder en gulder mekaar wel kun-t verdraagn that-PL $\left[\text { cl.they and } \text { you }_{\mathrm{PL}}\right]_{2 \mathrm{PL}}$ each.other PART can-2PL stand

'... that you and they can stand each other'

CoP in this example has the feature specification second person plural. This relation does not lead to an agreement affix on the complementizer. However, the relation with the third person plural first conjunct does lead to an agreement affix. In this case it is, as predicted, the relation with the first conjunct which gets realized.

\subsection{Conclusion}

This section has provided two additional arguments in support of the main claim of this paper. The first set of data, concerning modification and extraction of the subject in Tegelen Dutch versus Hellendoorn Dutch illustrated that CA in the latter dialect targets a Goal internal to the pronominal projection. Secondly, I have shown that CA with the first conjunct of a coordinated subject has the same distribution as CA in Hellendoorn Dutch: it is sensitive to modification and extraction of the subject. This strengthens the idea that Participant features are located in a similar structural position as the first conjunct of coordinated subjects, i.e. a high left peripheral position internal to the projection of the subject.

\section{Previous analyses}

As mentioned above, the phenomena of Double Agreement (DA) and Complementizer Agreement (CA) are a much debated issue in the literature on Germanic. This section discusses some previous analyses of these constructions and show why they should be discarded in favor of the analysis proposed above.

\subsection{The $\mathrm{T}^{\circ}$-to- $\mathrm{C}^{\circ}$-movement analysis of Complementizer Agreement and Double Agreement}

One of the most influential approaches to CA has been put forth by Jan-Wouter Zwart in a series of publications (cf. Zwart 1993, 1997, and 2001, henceforth referred to as Zwart). ${ }^{28}$ Zwart's main aim is to provide an analysis of verb movement in Dutch and

\footnotetext{
${ }^{27}$ Nieuwkerken-Waas Dutch does not allow modification of the subject or extraction of the subject.

${ }^{28}$ The analysis provided by Zwart $(1993,1997,2001)$ is comparable to several other analyses of CA. I do not discuss these analyses in depth here. The main argument I provide against Zwart's analysis of CA carries over to these other analyses. The first analysis that is comparable to the one provided by Zwart has been put forth by Hoekstra and Marácz (1989). The difference between these two analyses is that Zwart $(1993,1997,2001)$ assumes that $\mathrm{AgrS}^{\circ}$-to- $\mathrm{C}^{\circ}$-movement takes place in all Germanic dialects, whereas Hoekstra and Marácz (1989) argue that $\mathrm{AgrS}^{\circ}$-to- $\mathrm{C}^{\circ}$-movement only takes place in dialects with CA. I refer the reader to Zwart (1997: 145-154) for extensive discussion of this analysis. Furthermore,
} 
to show that Dutch is a head-initial language. He provides an analysis for the placement of the finite verb in the three major word orders in Dutch. Zwart argues that the CP layer is not projected in the SVO order. The CP-layer is projected in the CSOV and the (XP)VSO order, however. The head of the inflectional projection, $\operatorname{AgrS}^{\circ}$ in Zwart's analysis, moves to $\mathrm{C}^{\circ}$ when $\mathrm{C}^{\circ}$ is present. ${ }^{29}$ When $\mathrm{C}^{\circ}$ contains a complementizer, the finite verb normally does not move and stays in its (sentence-final) base position. When $\mathrm{C}^{\circ}$ is present but does not contain a complementizer, $\mathrm{V}^{\circ}$ has to move to $\mathrm{C}^{\circ}$. When $\mathrm{C}^{\circ}$ is not present, the finite verb moves to $\mathrm{AgrS}^{\circ}$.

One argument in favor of the idea that $\mathrm{AgrS}^{\circ}$ moves to $\mathrm{C}^{\circ}$ is the presence of agreement on the complementizer in several dialects. An important aspect of this analysis of $\mathrm{CA}$ is that the features of $\mathrm{AgrS}^{\circ}$ are checked once, namely with the subject, after which they get realized on both the finite verb and the complementizer. Put differently, according to this analysis there is only one set of phi-features checked in one feature checking operation that is expressed on two different clausal heads, the complementizer and the finite verb. This analysis predicts that the agreement morphology on the finite verb is identical to the agreement morphology on the complementizer.

The data discussed in Sect. 5 of this paper present a major problem for this analysis. Recall that there are dialects in which the agreement morphology on the complementizer expresses the features of the first conjunct of the coordinated subject, whereas the agreement morphology on the finite verb in the same clause spells out the feature specification of the coordinated subject as a whole. This is illustrated in the example in (70) from Tegelen Dutch.

$$
\begin{aligned}
& \text {... de-s doow en ich ôs treff-e } \\
& \text { that-2P.SG }\left[\text { you }_{\text {sg }} \text { and I }\right]_{1 \text { P.PL }} \text { each.other }{ }_{1 P . P L} \text { know-1PL } \\
& \text { '... that you and I know each other' }
\end{aligned}
$$

These data show that the relation between the complementizer and the subject is different from that between the finite verb and the subject. The agreement morphology on the finite verb expresses the features of the coordinated subject as a whole. The agreement morphology on the complementizer, on the other hand, expresses the features of the first conjunct of the coordinated subject. As such, these data constitute a considerable counterargument against Zwart's approach to CA.

Zwart also discusses DA-agreement in Hellendoorn Dutch. He argues that the DApattern in Hellendoorn Dutch shows that there are two paradigms for inflection, one

\footnotetext{
Watanabe (2000) also provides an analysis of CA that is comparable to Zwart's and differs only minimally from Zwart's analysis. Haegeman's (1992) account (but cf. also Bennis and Haegeman 1984 for a similar analysis) is in a sense also similar to the one proposed by Zwart. She also argues that the [Agr]-features of the complementizer are similar to the [Agr]-features on the inflectional head. The difference between these two analyses is that Haegeman (1992) assumes that the features on $\mathrm{C}^{\circ}$ are similar to those on $\mathrm{I}^{\circ}$ because both agree with the subject. As these two feature bundles are coindexed, they have to be identical. Zwart $(1993,1997,2001)$ on the other hand assumes that the features of $\mathrm{I}^{\circ}$ move to $\mathrm{C}^{\circ}$. As a consequence the feature bundle present on $\mathrm{C}^{\circ}$ is identical to the feature bundle of $\mathrm{I}^{\circ}$. See also Haegeman and van Koppen (2011) for additional arguments against these and several other analyses of CA that make use of the relation between $\mathrm{C}^{\circ}$ and $\mathrm{T}^{\circ}$

${ }^{29}$ The reason for $\mathrm{AgrS}^{\circ}$-to- $\mathrm{C}^{\circ}$-movement differs in the analyses discussed here. As this issue is orthogonal to the present paper I will leave it out of the discussion.
} 
related to $\mathrm{C}^{\circ}$ and one related to $\mathrm{AgrS}^{\circ}$. A verb or complementizer in $\mathrm{C}^{\circ}$ which agrees with a first person plural subject is inflected with a schwa-affix. A verb in $\mathrm{AgrS}^{\circ}$ that agrees with a first person plural subject on the other hand, is inflected with a $t$-affix. The data in (55) repeated here as (71) form a substantial problem for this account.

(71) WIEJ denkt Jan dat/* darr-e die pries ewönnen hebt, nie ZIEJ. we think Jan that/ that-1P.sG that prize won have not they

'WE John thinks won that prize, not THEY.'

The complementizer in this example does not show inflection. It is in $\mathrm{C}^{\circ}$, however, just like in the cases where the subject is not extracted. As such, these data show that the inflection on the complementizer is not dependent on the position of the complementizer or finite verb but on the position of the subject, contra Zwart's analysis.

\subsection{Prosodic domains: Ackema and Neeleman (2004)}

This section discusses the analysis of CA provided by Ackema and Neeleman (2004) (henceforth $A \& N$ ). The main ingredient of the account provided by $A \& N$ is that linear order is the main factor determining certain agreement patterns. The counterarguments to their account can therefore be interpreted as arguments against an analysis on the basis of linear ordering more in general (cf. for instance Fuss 2005; Miyagawa 2010). Apart from providing an analysis for CA, they also give an account along similar lines for the phenomenon of DA and for FCA in Dutch dialects.

$\mathrm{A} \& \mathrm{~N}$ assume that there are two ways of checking agreement features. The first one is to check features during the syntactic derivation. As a second option, they propose that features can be checked at PF, via so-called prosodic checking. Prosodic checking can take place when two sets of features are in one prosodic domain at PF. The general format of prosodic checking is provided in (72) (A\&N: 356).

$$
\begin{aligned}
& \{[\mathrm{A}(\mathrm{F} 1)(\mathrm{F} 2)(\mathrm{F} 3) \ldots][\mathrm{B}(\mathrm{F} 1)(\mathrm{F} 2)(\mathrm{F} 3) \ldots]\} \rightarrow \\
& \left\{\left[\mathrm{A}\left(\mathrm{F} 1_{\mathrm{i}}\right)\left(\mathrm{F} 2_{\mathrm{j}}\right)\left(\mathrm{F} 3_{\mathrm{k}}\right) \ldots\right]\left[\mathrm{B}\left(\mathrm{F} 1_{\mathrm{i}}\right)\left(\mathrm{F} 2_{\mathrm{j}}\right)\left(\mathrm{F} 3_{\mathrm{k}}\right) \ldots\right]\right\}
\end{aligned}
$$

This formula should be read as follows: if A and B are in one prosodic domain (indicated by the braces), the uninterpretable features of $\mathrm{A}$ are related to the matching interpretable features of $\mathrm{B}$ and/or vice versa. A\&N argue that $\mathrm{CA}$ is a typical example of prosodic checking. The complementizer and the subject are in one prosodic domain. As a consequence, the uninterpretable features of the complementizer can be checked (or rather identified) by those of the subject. ${ }^{30}$

There are some empirical problems with this account. First consider the data in (73) from Lapscheure Dutch (Liliane Haegeman p.c.).

\footnotetext{
${ }^{30}$ Note that the analysis proposed in this paper assumes that there is also a part of the agreement operation that takes place at the PF component, see section 4 above. The difference, however is that in the analysis proposed in this paper feature valuation always takes place during the syntactic component on the basis of hierarchical relations. In the prosodic checking account, the actual valuation of features takes place at the PF-branch on the basis of linear adjacency.
} 
a. Ik vinden da-n Jans joengers zovee geen ruzie zou meugen I think that-pl Jans boys so.much no argument should can moaken.

make

'I think that Jan's boys shouldn't make so many arguments.'

b. ...* da-n/ da die joengers under moeder dood is that-3P.PL/ that-sg those boys their mother dead is

'... that those boys' mother is dead'

The data in (73a) show that the head noun die joengers 'those boys' is in the same prosodic domain as the complementizer, since the complementizer agrees with this head noun, and CA is the result of checking within a prosodic domain. This means that the possessors Jans 'Jans' and die joengers 'those boys' are also within this prosodic domain. As such, we would expect CA with these possessors to be possible. This is not the case, however, as illustrated by example (73b).

Secondly, consider again the data concerning modification of the subject provided in Sect. 4 above.

$$
\text { ... dat/ *darr-e zölfs wiej de wedstrijd wint }
$$
that/ that-1P.sG even we the game win

'... that we even win the game'

$$
\text { ... de-s } /^{*} \text { ?det auch doow merge kum-s }
$$

Tegelen Dutch that-2P.SG $/$ that also you SG $_{\text {tomorrow come-2P.SG }}$

'... that you too will come tomorrow'

These data show that the complementizer in Tegelen Dutch is inflected when the subject pronoun is modified by the focus particle auch 'also'. The complementizer in the dialect of Hellendoorn, on the other hand, cannot be inflected when the subject is modified by a focus particle. This is unexpected from the point of view of A\&N's analysis. They argue that $\mathrm{CA}$ is the result of prosodic checking between the complementizer and the subject. The complementizer and the subject have to be in the same prosodic domain in order for CA to appear. The question arises whether a focus particle breaks up the prosodic domain or not. If it does, CA is expected to be blocked by a focus particle. If not, CA should not be able to be blocked by a focus particle. The data in (75) show that the complementizer and the subject pronoun are in the same prosodic domain, as the complementizer shows inflectional morphology. The data in (74) on the other hand, show that the complementizer and the subject are not in the same prosodic domain, as in this case agreement on the complementizer is impossible. In other words, A\&N's analysis does not provide a means to account for the discrepancy between (74) and (75) without having to stipulate that a focus particle does break up the prosodic domain in the dialect of Hellendoorn, whereas it does not in the dialect of Tegelen Dutch.

Now let us consider DA. A\&N argue that Hellendoorn Dutch has the same rule at $\mathrm{PF}$ to regulate $\mathrm{CA}$ as, for instance, Tegelen Dutch above. The difference between a DA dialect like Hellendoorn Dutch and a non-DA dialect like Tegelen Dutch, is that Hellendoorn Dutch has an additional allomorphy rule. A\&N argue that Hellendoorn 
Dutch has two affixes associated with agreement in the first person plural: a $t$-affix and a schwa-affix. The schwa-affix is regarded as an allomorph of the $t$-affix that is inserted if the structural description in (76) is met (cf. A\&N: 368). ${ }^{31}$

$$
\begin{aligned}
& \left\{\left[\mathrm{C}\left(\mathrm{Prt}_{\mathrm{i}}\right)\left(\mathrm{Add}_{\mathrm{j}}\right)\left(\mathrm{Plr}_{\mathrm{k}}\right)\right]\left[\mathrm{D}\left(\mathrm{Prt}_{\mathrm{i}}\right)\left(\mathrm{Add}_{\mathrm{j}}\right)\left(\mathrm{Plr}_{\mathrm{k}}\right)\right]\right\} \rightarrow \\
& \left\{\left[\mathrm{C}\left(\mathrm{Prt}_{\mathrm{i}}\right)\left(\mathrm{Add}_{\mathrm{j}}\right)\left(\mathrm{Plr}_{\mathrm{k}}\right) F\right]\left[\mathrm{D}\left(\operatorname{Prt}_{\mathrm{i}}\right)\left(\mathrm{Add}_{\mathrm{j}}\right)\left(\mathrm{Plr}_{\mathrm{k}}\right)\right]\right\}
\end{aligned}
$$

The $F$ in the second line of this description represents the feature that requires the schwa-affix to be inserted. This means that when the complementizer checks its features against the subject via prosodic checking, the structural description in the first line of the rule in (76) arises. On the basis of this, the schwa-affix is inserted on the complementizer rather than the $t$-affix. The same holds when the verb precedes the subject. In this case, the verb and the subject are in one prosodic domain. The features of the verb match the features of the subject. Therefore, the linear string is similar to the first line of the rule in (76) and the schwa-affix appears on the finite verb. Furthermore, A\&N show that when an adverb intervenes between the verb or the complementizer and the subject, the schwa-affix cannot appear, as expected under their analysis. In this case, the subject and the finite verb or the subject and the complementizer are not in one prosodic domain. The allomorphy rule does not apply, and hence the schwa-affix cannot appear.

The question arises how this analysis of DA can be distinguished from the analysis put forth in this paper, in which agreement is based on hierarchical relations, rather than on linear adjacency. Consider again the examples in (74) and (75). A\&N argue that the schwa-affix appearing on the complementizer in Hellendoorn Dutch is an allomorph that appears when the condition in (76) is met: i.e. a complementizer and a subject with identical features are in the same prosodic domain. CA occurs under similar circumstances: a complementizer with phi-features and a subject are in one and the same prosodic domain. It is expected that CA in a dialect like Tegelen Dutch and CA in Hellendoorn Dutch behave similarly, as the conditions for CA in Tegelen Dutch, and the allomorphy rule in Hellendoorn Dutch are similar. This does not appear to be the case, however. The allomorphy rule for Hellendoorn Dutch appears to be sensitive to the presence of a focus particle intervening between the complementizer and the subject, whereas CA in Tegelen Dutch is not. This is unexpected as both CA in Hellendoorn Dutch and in Tegelen Dutch are based on linear adjacency. When a focus particle blocks the effects of linear adjacency in the one case, it is also expected to be blocked in the other case. This expectation is not met by the data.

Finally, A\&N provide a tentative analysis of FCA in Dutch dialects based on the data presented in van Koppen (2003). They argue that agreement between the complementizer and the first conjunct of a coordinated subject is facilitated by the fact that these items are in one prosodic domain at PF. This is illustrated in (77) (from A\&N: 373).

$$
\left[\mathrm{CP} \mathrm{C}^{\circ}[\mathrm{IP}[\mathrm{DP} \text { and DP }][\mathrm{VP} \ldots]]\right] \rightarrow\{\mathrm{C} \mathrm{DP}\}\{\text { and DP }\}\{\ldots\}
$$

As the complementizer and the first conjunct of the coordinated subject are in one domain, the first conjunct can check the features of this complementizer via prosodic

${ }^{31}$ Prt $=$ Participant, Add $=$ addressee, Plr $=$ Plural. 
checking. As a consequence, the complementizer shows agreement with the first conjunct. $A \& N$ (p. 374) account for this agreement pattern with the assumption that there is "an 'early' restructuring rule which erases the phi-boundaries [prosodic boundaries; MvK] between conjuncts".

A\&N show that subject modification in Tegelen Dutch provides an argument in favor of their account. When a focus particle modifies the subject, the first conjunct of the coordinated subject and the complementizer are no longer in one domain. A\&N propose that adding a focus particle to the subject forces both conjuncts of the coordinated subject to be interpreted in the same prosodic domain. The prosodic phrasing they come up with is represented in (78) (from A\&N: 374).

$$
\begin{aligned}
& {\left[\mathrm{CP}^{\circ} \mathrm{C}^{\circ}[\mathrm{IP}[\text { modifier }[\mathrm{DP} \text { and DP }]][\mathrm{vP} \ldots]]\right] \rightarrow} \\
& \left\{\mathrm{C}^{\circ} \text { modifier DP and DP }\right\}\{\ldots\}
\end{aligned}
$$

As a consequence, the first DP is no longer adjacent to $\mathrm{C}^{\circ}$, therefore FCA on the complementizer should be impossible. This prediction is not fully met by the data, as shown in example (62) above. However, there seems to be a more fundamental problem with this account. It is not exactly clear why FCA should be blocked in this case. Although the complementizer and the first conjunct are not adjacent, they are still part of the same prosodic domain. Hence, prosodic checking should be possible. However, A\&N seem to assume (but as far as I can see they do not make this explicit) that it is not enough for two elements to be in a similar prosodic domain to induce Prosodic Checking, these elements should also be adjacent.

\section{Conclusion}

I have argued that the phi-features of pronouns consist of participant and individuation features in the sense of Harley and Ritter (2002). These two sets of features are merged in discrete syntactic positions. More specifically, I have argued that the Participant features occupy the highest specifier position in the left periphery of the pronominal projection, whereas the Individuation features are merged lower in the structure. The number specification of the participant features can (but does not necessarily have to be) different from the number specification of the individuation features. For instance, first person plural pronouns consist of first person singular participant features and plural individuation features. The participant features and the individuation features are merged in the course of the derivation and reside on the maximal projection of the pronominal projection. The Participant features (occupying a high left peripheral position) are available for the syntactic operation Agree. This potentially results in the situation in which a Probe agrees with the singular participant features of the pronoun, whereas the pronoun itself is plural. I would like to stress at this point that the implementation of the pronominal structure I have used in this paper, is actually orthogonal to the claim made in this paper. The conclusion that Participant features are merged as a discrete set of features available to syntactic processes like Agree can be implemented in other, even non-phrasal, views on the syntax of pronouns as well.

The arguments in favor of this account came from complementizer agreement and verbal agreement with pronouns in Hellendoorn Dutch. I have shown that CA with 
first person plural subjects in this dialect reflects first person singular features, i.e. the features of the Participant node. The idea that the complementizer agrees with a Goal inside the pronominal projection was confirmed by the behavior of this type of CA regarding extraction and modification of the subject. Furthermore, I have shown that the distribution of CA with the first conjunct of a coordinated subject, again a Goal inside the maximal projection of the subject, displays the same distributional pattern as CA in Hellendoorn Dutch.

A side-effect of this analysis is that we have established that there are two types of CA dialects: the Hellendoorn Dutch type (in which the complementizer agrees with the Participant features) and the Tegelen Dutch type (in which the complementizer agrees with the features present on the maximal projection of the pronoun). The former dialect displays a DA-pattern and CA disappears when the subject is modified or extracted. In the latter there is no DA-pattern and CA is insensitive to modification or extraction of the subject.

Acknowledgements I would like to thank Jonathan Bobaljik, Jeroen Van Craenenbroeck, Marcel den Dikken, Johan Rooryck, and two anonymous NLLT reviewers for their invaluable input. Needless to say, all errors and shortcomings are my own.

Open Access This article is distributed under the terms of the Creative Commons Attribution Noncommercial License which permits any noncommercial use, distribution, and reproduction in any medium, provided the original author(s) and source are credited.

\section{References}

Abney, Steven. 1987. The English noun phrase in its sentential aspect. PhD dissertation, MIT.

Ackema, Peter, and Ad Neeleman. 2004. Beyond morphology: Interface conditions on word formations. Oxford: Oxford University Press.

Aoun, Joseph, Elabbas Benmamoun, and Dominique Sportiche. 1994. Agreement, word order, and conjunction in some varieties of Arabic. Linguistic Inquiry 25: 195-220.

Barbiers, Sjef. 1995. The syntax of interpretation. PhD dissertation, Leiden University, The Netherlands. Barbiers, Sjef. 2003. Generalized focus particle doubling. Handout, CGSW 18, University of Durham.

Bayer, Joseph. 1984. COMP in Bavarian syntax. The Linguistic Review 3: 209-274.

Bennis, Hans, and Liliane Haegeman. 1984. On the status of agreement and relative clauses in West Flemish. In Sentential complementation: Proceedings of the international conference held at Ufsal, Brussels, eds. Wim de Geest and Yvan Putseys, 33-53. Dordrecht: Foris.

Bernstein, Judy. 1993. The syntactic role of word markers in null nominal constructions. Probus 5: 5-38.

den Besten, Hans. 1989. Studies in West Germanic syntax. PhD dissertation, University of Tilburg, The Netherlands.

den Besten, Hans. 1996. Associative DPs. In Linguistics in the Netherlands, eds. Crit Cremers and Marcel den Dikken, 13-24. Amsterdam: John Benjamins.

Bianchi, Valentina. 2006. Person and the left periphery. Ms., University of Sienna, Italy.

Bošković, Željko. 2008. Unifying first and second conjunct agreement. Ms., University of Connecticut.

Büring, Daniel, and Katharina Hartmann. 2001. The syntax and semantics of focus-sensitive particles. Natural Language and Linguistic Theory 19(2): 229-281.

Cardinaletti, Anna. 1998. On the deficient/strong opposition in possessive systems. In Possessors, predicates and movement in the Determiner Phrase, eds. Alexiadou Artemis and Chris Wilder, 17-53. Amsterdam: John Benjamins.

Cardinaletti, Anna, and Michal Starke. 1999. The typology of structural deficiency: A case study of the three classes of pronouns. In Clitics in the languages of Europe, ed. Henk van Riemsijk, 145-233. Berlin: Mouton de Gruyter.

Carstens, Vicky. 2002. Rethinking complementizer agreement: Agree with a case-checked Goal. Linguistic Inquiry 34(3): 393-412. 
Chomsky, Noam. 1986. Barriers. Cambridge: MIT Press.

Chomsky, Noam. 1995. The minimalist program. Cambridge: MIT Press.

Chomsky, Noam. 2000. Minimalist inquiries: The framework. In Step by step: Essays on minimalist syntax in honor of Howard Lasnik, eds. Robert Martin, David Michaels, and Juan Uriagereka, 89-155. Cambridge: MIT Press.

Corbett, Greville. 2006. Agreement. Cambridge: Cambridge University Press.

Corver, Norbert, and Denis Delfitto. 1999. On the nature of pronoun movement. In Clitics in the languages of Europe, ed. Henk van Riemsdijk, 799-861. Berlin: Mouton de Gruyter.

van Craenenbroeck, Jeroen, and Marjo van Koppen. 2002. The locality of agreement and the CP-domain. Handout, GLOW 2002, Amsterdam.

van Craenenbroeck, Jeroen, and Marjo van Koppen. 2003. Congruentie en localiteit in de Nederlandse dialecten [Congruence and locality in Dutch dialects]. In Taal en Tongval Themanummer Dialectsyntaxis, 63-86.

van Craenenbroeck, Jeroen, and Marjo van Koppen. 2008. Pronominal doubling in Dutch dialects. In $M i$ crovariation in syntactic doubling, eds. Sjef Barbiers, Olaf Koeneman, and Marika Lekakou, Vol. 36 of Syntax and semantics, 207-239. Bingley: Emerald.

Cysouw, Michael. 2001. The paradigmatic structure of person marking. PhD dissertation, University of Nijmegen, The Netherlands.

Dalrymple, Mary, and Robert Kaplan. 1997. A set-based approach to feature resolution. In Proceedings of the LFG 97 conference, eds. Miriam Butt and Tracy Halloway King, San Diego: CSLI.

Déchaine, Rose-Marie, and Martina Wiltschko. 2002. Decomposing pronouns. Linguistic Inquiry 33(3): 409-442.

Deunk, G.H. 1977. Grammatica van het Winterswijks. Sasland: Groningen.

den Dikken, Marcel, Anikó Lipták, and Zsófia Zvolenszky. 2001. On inclusive reference anaphora: New perspectives from Hungarian. In WCCFL 20 proceedings, eds. Karine Megerdoomian and Leora Barel, 137-149. Somerville: Cascadilla Press.

Forchheimer, Paul. 1953. The category Person in language. Berlin: Walter de Gruyter.

Fuss, Erik. 2005. The rise and fall of agreement. Amsterdam: John Benjamins.

Gruber, Bettina. 2008. Complementiser agreement: New evidence from the Upper Austrian variant of Gmunden. MA thesis, University of Vienna.

de Haan, Ger. 1997. Voegwoordcongruentie in het Fries [Complementizer agreement in Frisian]. In Vervoegde voegwoorden [Inflected complementizers], eds. Hoekstra, Eric and Caroline Smits, 50-67. Amsterdam: P.J. Meertens-Instituut.

Haegeman, Liliane. 1992. Theory and description in generative syntax: A case study in West Flemish. Cambridge: Cambridge University Press.

Haegeman, Liliane, and Marjo van Koppen. 2011. Complementizer agreement and the relation between $\mathrm{T}^{\circ}$ and $\mathrm{C}^{\circ}$. http://ling.auf.net/lingBuzz/001181.

Halle, Morris, and Alec Marantz. 1993. Distributed Morphology and the pieces of inflection. In The view from building 20, eds. Ken Hale and Samuel Keyser, 111-176. Cambridge: MIT Press.

Halle, Morris, and Alec Marantz. 1994. Some key features of Distributed Morphology. In MIT working papers in linguistics 21, eds. Andrew Carnie, Heidi Harley, and Tony Bures, 275-288. Cambridge: MITWPL.

Halle, Morris. 1997. Distributed Morphology: Impoverishment and fission. In MIT working papers in linguistics 30, eds. Benjamin Bruening, Kang Yoonjung, and Martha McGinnis, 425-449. Cambridge: MITWPL.

Harley, Heidi, and Elizabeth Ritter. 2002. Person and number in pronouns: A feature geometric analysis. Language 78(3): 482-526.

Harley, Heidi, and Rolf Noyer. 1999. Distributed morphology. Glot International 4(4): 3-9.

Harris, Jim. 1991. The exponence of gender in Spanish. Linguistic Inquiry 22: 27-62.

Hoekstra, Eric, and Caroline Smits. 1997. Vervoegde voegwoorden in de Nederlandse dialecten [Complementizer agreement in Dutch dialects]. In Vervoegde voegwoorden [Inflected complementizers], eds. Eric Hoekstra and Caroline Smits, 6-30. Amsterdam: P.J. Meertens-Instituut.

Hoekstra, Jarich, and László Marácz. 1989. On the position of inflection in West Germanic. Working Papers in Scandinavian. Syntax 44: 75-88.

Huang, James. 1982. Move wh in a language without wh-movement. The Linguistic Review 82(1): 369416.

Iljic, Robert. 1994. Quantification in Mandarin Chinese: Two markers of plurality. Linguistics 32: 91-116. Johannessen, Janne. 1998. Coordination. Oxford: Oxford University Press. 
Kayne, Richard. 1994. The antisymmetry of syntax. Cambridge: MIT Press.

van Koppen, Marjo. 2003. A new view on First Conjunct Agreement: Evidence from Dutch dialects. In Studies on agreement, eds. João Costa and Maria Christina Figueiredo Silva, 121-141. Amsterdam: John Benjamins.

van Koppen, Marjo. 2005. One probe-two goals: Aspects of agreement in Dutch dialects. PhD dissertation, University of Leiden, The Netherlands.

van Koppen, Marjo. 2008. Agreement with coordinated subjects: A comparative perspective. Linguistic Variation Yearbook 7: 121-161.

van Koppen, Marjo, and Johan Rooryck. 2008. Resolving resolution: Underspecification and the law of coordination of likes. Ms., Utrecht University. Leiden University.

Lyons, John. 1968. Introduction to theoretical linguistics. Cambridge: Cambridge University Press.

May, Robert. 1985. Logical form. Cambridge: MIT Press.

Miyagawa, Shigeru. 2010. Why Agree? Why Move? Unifying agreement-based and discourse configurational languages. Cambridge: MIT Press.

Mühlhäusler, Peter, and Rom Harré. 1990. Pronouns and people: The linguistic construction of social and personal identity. Oxford: Blackwell.

van Oostendorp, Marc. 1998. Schwa in phonological theory. Glot International 3(5): 3-8.

Pesetsky, David, and Esther Torrego. 2001. T-to-C movement: Causes and consequences. In Ken Hale: $a$ life in language, ed. Michael Kenstowicz, 355-426. Cambridge: MIT Press.

Platzack, Christer. 2004. Agreement and the person phrase hypothesis. Working Papers in Scandinavian Syntax 73: 83-112.

Poletto, Cecilia. 2000. The higher functional field: Evidence from Northern Italian dialects. Oxford: Oxford University Press.

Pollock, Jean-Yves. 1989. Verb movement, Universal Grammar, and the structure of IP. Linguistic Inquiry 20: $365-424$.

Postal, Paul. 1966. On so-called pronouns in English. In Report of the 17th annual round table meeting on languages and linguistics, ed. Francis P. Dineen, 177-206. Washington: Georgetown University Press.

Progovac, Liljana. 1998. Structure for coordination. Glot International 3: 7-38.

Roehrs, Dorian. 2005. Pronouns are determiners after all. In The function of function words and functional categories, eds. Marcel den Dikken and Christina Tortora, 251-285. Amsterdam: John Benjamins.

Rooryck, Johan. 2001. The morphosyntactic structure of articles and pronouns in Dutch. In Germania et alia: A linguistic webschrift for Hans den Besten, eds. Jan Koster and Henk van Riemsdijk,

Rooryck, Johan. 2006. Binding into pronouns. In Language in mind: A tribute to Neil Smith on the occasion of his retirement, eds. Robyn Carston, Diane Blakemore, and Hans van de Koot, Vol. 116 of Lingua, 1561-1579.

Ross, Robert. 1967. Constraints on variables in syntax. PhD dissertation, MIT.

Rullmann, Hotze. 2004. First and second person pronouns as bound variables. Linguistic Inquiry 35: 159168.

Sauerland, Uli. 2004. A new semantics for number. Ms., University of Tübingen, Germany.

Sauerland, Uli, Jan Anderssen, and Kazuko Yatsushiro. 2004. The plural involves comparison. Ms., University of Tübingen, University of Connecticut, University of Massachusetts.

Shlonsky, Ur. 1989. The hierarchical representation of agreement. Ms., University of Geneva, Switzerland.

Soltan, Usama. 2007. On formal feature licensing in minimalism: Aspects of standard Arabic morphosyntax. PhD dissertation, University of Maryland.

Vassilieva, Masha, and Richard Larson. 2005. The semantics of the plural pronoun construction. Natural Language Semantics 13(2): 101-124.

Watanabe, Akira. 2000. Feature copying and binding. Syntax 3: 159-181.

Zwart, Jan-Wouter. 1993. Dutch syntax: A minimalist approach. PhD dissertation, University of Groningen. The Netherlands.

Zwart, Jan-Wouter. 1997. A minimalist approach to the syntax of Dutch. Dordrecht: Kluwer.

Zwart, Jan-Wouter. 2001. Syntactic and phonological verb movement. Syntax 4(1): 34-62. 